\title{
Indicadores para la medición de la respuesta de los estados en el abordaje de la trata de personas ${ }^{1}$
}

\section{Indicators for measuring the response of states in the approach to trafficking in persons}

\section{Jakeline Vargas Parra $(\mathbb{D}$}

Universidad Autónoma de Bucaramanga

jvargas557@unab.edu.co

\section{Johana Reyes Jaimes (D)}

Universidad Manuela Beltrán - Seccional Bucaramanga

johana.reyes@docentes.umb.edu.co

\section{Mónica Chía Cifuentes}

Universidad Autónoma de Bucaramanga

mchia420@unab.edu.co

\section{Resumen}

Las legislaciones nacionales y las politicas públicas promulgadas para el abordaje de la trata de personas requieren ser monitoreadas y evaluadas para verificar su cumplimiento, efectividad e impacto sobre la vida de las personas. Este trabajo aporta escalas de evaluación, además de la clasificación y el análisis de 396 indicadores identificados a partir de una revisión de las propuestas de medición a nivel global, regional, nacional y subnacional. Los autores de dichas mediciones son entes académicos, gubernamentales, no gubernamentales y organismos supranacionales. Para ellos mismos, los hallazgos de este trabajo son un insumo fundamental, pues sirve para el diseño de estrategias de seguimiento, monitoreo y evaluación de la respuesta gubernamental al problema de la trata de personas.

Palabras claves: trata de personas, indicadores, monitoreo, evaluación, políticas públicas.

\section{Abstract}

National laws and public policies promulgated to address trafficking in persons in different countries of the world, need to be monitored and evaluated with a view to generating evidence regarding compliance, effectiveness and real impacts on people's lives. In this sense, this work provides evaluation scales and the classification and analysis of 396 indicators, identified from a literature review in which proposals for measurement were analyzed at a global, regional, national and subnational level. The authors of these measurements correspond to academic, governmental, non-governmental actors and supranational organizations, the same ones for whom the findings of this work constitute a fundamental input for

${ }^{1}$ Este artículo se realizó en el marco del proyecto de investigación E78021 "Trata de personas en Colombia: indicadores para una estrategia de monitoreo desde las regiones", es financiado por la convocatoria bienal interna de la UNAB 2017-2018 y ejecutado en alianza con la Universidad Manuela Beltrán, la Universidad del Norte, la Universidad Libre de Pereira y la Corporación CreSer en el marco de un trabajo colaborativo desarrollado en el Capítulo Colombia del Observatorio Latinoamericano sobre trata y tráfico de personas -ObservaLAtata- http://observalatrata.com 
the design of follow-up, monitoring and evaluation strategies of the government response in the approach to trafficking in persons.

Keywords: Human Trafficking, indicators, monitoring, evaluation, public policy.

Articulo: Recibido el 29 de abril de 2019 y aprobado el 24 de junio de 2019.

\section{Cómo citar este articulo:}

Vargas-Parra, J., Reyes Jaimes, J., Chia-Cifuentes, M. (2019). Indicadores para la medición de la respuesta de los estados en el abordaje de la trata de personas. Reflexión Politica 21(42), pp. 44-78. doi: 10.29375/01240781.3596

\section{Introducción}

En el año 2000 la Convención de las Naciones Unidas contra la Delincuencia Organizada Transnacional reconoció la trata de personas como una de las manifestaciones de la delincuencia organizada e instó a los estados de origen, tránsito y destino de las víctimas a incorporar su abordaje en la agenda pública a través de la ratificación del Protocolo de Palermo como un instrumento de política regulatoria internacional destinado a prevenirla, reprimirla y sancionarla.

En consecuencia, los distintos estados que ratificaron dicho instrumento, han diseñado e implementado legislaciones nacionales y políticas públicas para enfrentar la trata de personas, adquiriendo compromisos que requieren ser monitoreados y evaluados en perspectiva de generar evidencia respecto de su cumplimiento, efectividad e impactos reales sobre la vida de las personas. Con el propósito de generar estos indicadores y su medición, resulta fundamental la movilización de actores con influencia para "crear un entendimiento común sobre cómo encuadrar, analizar y responder ante un problema particular" (Davis y Kingsbury, 2014, p. 481). Al respecto, pueden señalarse las tres iniciativas de monitoreo y evaluación con mayor difusión a nivel global. A saber, el Informe Mundial sobre la Trata de Personas de la Oficina de las Naciones Unidas contra la Droga y el Delito (UNODC), el Informe sobre la Trata de Personas del Departamento de Estado de los Estados Unidos y el índice Global de Esclavitud de la Fundación Walk Free. Si bien, los actores que lideran estas iniciativas de medición han logrado posicionar estimaciones estadísticas sobre la situación de la trata de personas en el mundo e indicadores que califican la acción de los gobiernos de los distintos países en el enfrentamiento de la problemática, resulta de particular interés indagar sobre la existencia de otros actores que hayan desarrollado metodologías e instrumentos de medición para evaluar la gestión de los gobiernos.

En Colombia, las acciones contra la trata están enmarcadas en la Ley 985 del 2005 y en la Estrategia Nacional para la Lucha Contra la Trata de Personas aprobada en el Decreto 1036 del 2016, que afronta la problemática desde cuatro ejes: prevención; investigación y judicialización; asistencia y protección a víctimas; y cooperación internacional. Sin embargo, a pesar de contar con un marco normativo y con amplias políticas sobre el tema, la lucha contra la trata se enfrenta actualmente a una serie de retos que el Estado colombiano no ha sabido abordar adecuadamente (Reyes, Vargas, y Aceros, 2018). Reflejo de ello, por ejemplo, es que no se cuenta con un sistema de evaluación que garantice la adecuada implementación (y eventual mejoramiento) de las medidas de protección y atención a las víctimas (Ministerio del Interior et al., 2014).

Este trabajo tiene como propósito el de ser un insumo fundamental para el diseño de estrategias de seguimiento, monitoreo y evaluación de la respuesta gubernamental en el abordaje de la trata de personas. En primer lugar, se hace una aproximación a las principales mediciones a nivel global y regional, enfatizando en las escalas de evaluación con las que califican la respuesta de los estados. En segundo lugar, se presenta 
una clasificación y un análisis de 396 indicadores, esto estructurado en 7 dimensiones.

\section{Metodologia}

La investigación se realizó con fundamento en la revisión documental, definida como "un trabajo constitutivo donde la interpretación, la crítica y la argumentación racional, juegan un papel preponderante porque permiten llevar a cabo inferencias y relaciones" (Hoyos, 2000, p.25). Después de la búsqueda de palabras clave (trata de personas, medición de indicadores, evaluación de políticas públicas contra la trata, trafficking in persons, human trafficking, monitoring e indicators) en bases de datos como Scopus, Google Académico, DOAJ, SSRN, ELSEVIER y publicaciones de las páginas oficiales de algunos organismos como OIM, UNODC, Departamento de Estado de los Estados Unidos y Walk Free Foundation, se seleccionaron 32 documentos relacionados directamente con la evaluación y el monitoreo de acciones gubernamentales contra la trata de personas. El $50 \%$ de los documentos analizados está escrito en español y el 50\% en inglés. Se identificaron cuatro tipos de actores responsables de las propuestas de medición así: gubernamentales, no gubernamentales, académicos y organismos supranacionales.

Esta primera fase de búsqueda permitió dilucidar de manera general el panorama de los estudios de la evaluación y el monitoreo de políticas sobre trata de personas en Colombia y en el mundo. Se encontró que, de los 32 documentos, 15 desarrollan algún tipo de indicador de medición. Los 17 documentos restantes aportan para la construcción de indicadores en el tema, a través de perspectivas teóricas o críticas frente a los actuales sistemas de medición. Por ejemplo, Kelley \& Simmons (2015), exponen el efecto de las mediciones con indicadores cuantitativos en la tipificación del delito de trata de personas en el mundo.

Con respecto a los 15 documentos que efectivamente contenían indicadores, fueron categorizados en tres niveles: global, regional y nacional/ subnacional, atendiendo a un criterio de cobertura geográfica de la medición que proponían. Posteriormente, se seleccionaron y analizaron 7 documentos que arrojaron 396 indicadores clasificados en el
Anexo 1 de la siguiente manera: (1) Marcos normativos, (2) Detección, identificación y dinámica de la trata de personas, (3) Prevención de la trata de personas, (4) Protección y asistencia, (5) Penalización, sanción y reparación, (6) Coordinación, cooperación, sostenibilidad y acceso a recursos y (7) Generación y gestión del conocimiento. Esta clasificación fue establecida atendiendo al documento Principios y Directrices recomendados sobre derechos humanos y trata de personas (ACNUDH, 2010) y a los ejes de la estrategia nacional de lucha contra la trata de personas en Colombia 2012-2018.

\section{Resultados y discusión}

\section{Mediciones y escalas de evaluación de la respuesta de los estados en el abordaje de la trata de personas a nivel global y regional.}

La ausencia de un organismo formal, dentro del Protocolo de Palermo, facultado para hacer seguimiento a los compromisos adquiridos por los países, dificulta la medición de las respuestas estatales contra la trata de personas (Gallagher \& Chuang, 2012). Sin embargo, la creciente preocupación de gobiernos y organizaciones internacionales ha generado que diversos actores diseñen y apliquen modelos para la detección de la trata de personas y para la evaluación y el seguimiento de las acciones gubernamentales.

\subsection{Mediciones y escalas de evaluación a nivel global}

En el mundo se destacan tres grandes mediciones: El Trafficking in persons report (2018), el Global report on trafficking in Persons (2018) y el Global Slavery Index (2018). Dichos estudios sobresalen entre las mediciones, principalmente porque generan presión en los estados, al calificarlos de acuerdo con cumplimiento de sus obligaciones al enfrentar el problema, lo cual permite la comparación entre las diferentes naciones. Esta característica es parte de la función de las mediciones numéricas globales en la actualidad, dado que sirve como herramienta de presión social en las relaciones internacionales y hace parte de las estrategias de 
Tabla 1.

Comparativo estimaciones estadísticas del delito de trata de personas en el mundo

\begin{tabular}{|c|c|c|c|}
\hline & $\begin{array}{l}\text { Trafficking in persons } \\
\text { report } \mathbf{( 2 0 1 8 )}\end{array}$ & $\begin{array}{l}\text { Global report on trafficking } \\
\text { in Persons (2018) }\end{array}$ & $\begin{array}{l}\text { Global Slavery Index } \\
\text { (2018) }\end{array}$ \\
\hline $\begin{array}{l}\text { Número de víctimas } \\
\text { reportadas en último } \\
\text { informe }\end{array}$ & 68.453 & 24.000 & 40.3 millones \\
\hline Definición del dato & $\begin{array}{l}\text { Número de víctimas } \\
\text { identificadas en el } 2016 \\
\text { (P.43) }\end{array}$ & $\begin{array}{l}\text { Número de víctimas de } \\
\text { trata detectadas en el } 2016 \\
\text { (p.7) }\end{array}$ & $\begin{array}{l}\text { Personas que se } \\
\text { encuentran en condición } \\
\text { de esclavitud moderna en } \\
2016 \\
\text { (p.2) }\end{array}$ \\
\hline Número de países & 190 países & 97 países * & 167 países \\
\hline Fuente de los datos & $\begin{array}{l}\text { Datos proporcionados por } \\
\text { gobiernos extranjeros y } \\
\text { otras fuentes y revisadas } \\
\text { por el Departamento de } \\
\text { Estado los Estados Unidos. }\end{array}$ & $\begin{array}{l}\text { Datos nacionales } \\
\text { reportadas a UNODC en el } \\
2016 .\end{array}$ & $\begin{array}{l}\text { Modelo predictivo basado } \\
\text { en datos de la encuesta } \\
\text { representativa nacional } \\
\text { implementada por Gallup } \\
\text { world poll y del modelo } \\
\text { de vulnerabilidad de la } \\
\text { fundación. }\end{array}$ \\
\hline
\end{tabular}

Fuente: elaboración propia con base en Department of State (2018), Oficina de las Naciones Unidas contra la Droga y el Delito (2018) y Walk Free Foundation (2018).

* Pese a que el reporte del 2018 de la UNODC realiza el análisis de 142 países (UNODC, 2018, p. 15), las cifras de víctimas detectadas que reporta corresponden únicamente a los datos de 97 países según la tabla presente de la página 7 de dicho documento.

soft power ${ }^{1}$ (Kelley \& Simmons, 2015). Otro de los aspectos a destacar de estas tres mediciones, es que todas ellas aproximan o cuantifican el fenómeno de la trata a nivel mundial. Estas estadísticas, en algunos casos, suelen ser meras estimaciones del fenómeno, puesto que las metodologías usadas son poco claras. El fenómeno es de difícil detección para las autoridades y en muchos casos los países no cuentan con cifras fiables del delito (Gallagher \& Chuang, 2012; Guth, Anderson, Kinnard \&Tran, 2014). En la Tabla 1 se observan comparativamente las cifras del fenómeno que cada una de las tres mediciones reportó en el año $2018^{2}$.

Los datos arrojados por las diferentes mediciones muestran gran disparidad en el número de víctimas. Esto se debe a las metodologías y fuentes de información usadas en cada informe. Principalmente, las estimaciones del Global Slavery Index (2018) arrojan cifras alarmantes. Su metodología se fundamentó en los datos proporcionados por la Organización Internacional del trabajo (OIT), la Organización Internacional de las Migraciones (OIM) y en la aplicación de 51 modelos de encuestas a más de 71.000 personas en 48 países (Walk Free Foundation, 2018, p.167). Este cálculo de víctimas se hace a partir de la medición de la vulnerabilidad y los factores de riesgo.

En la actualidad, el informe que mayor influencia tiene en la comunidad internacional es el Trafficking in Persons Report (TIP). Según Kelley y Simmons (2015), ha influenciado el aumento de la tipificación del delito en los países observados. El

1 Soft power o 'poder suave' es un concepto de la ciencia política introducido por Nye (2004), para definir una forma de poder de los estados. Este se basa en la influencia de un actor sobre otro a través de la simple persuasión. "La persuasión para adherirse a normas y aspiraciones. No se trata de forzar, sino de co-optar. Parte de la atracción más que de la coerción. En lugar de pensar en poder "sobre" se piensa en poder "con", al buscar que el otro se adhiera a valores y/o una cultura" (Añorve, 2016, p.46). En el campo de las mediciones con indicadores de desempeño, se ha establecido su influencia en algunos casos sobre las políticas de gobierno, lo que haría parte de estrategia de poder suave.

2 Los informes globales tomados para el análisis son los más recientes, correspondientes al 2018. Sin embargo, el Global report on trafficking in Persons (2018) y el Global Slavery Index (2018), que son mediciones bienales globales, tienen su último informe en el año 2016, a la fecha en que se escribió este artículo. 
líder de este reporte es el Departamento de Estado del gobierno de los Estados Unidos. Su periodicidad es anual y a la fecha se han emitido 18 reportes desde el año 2001.

Por su parte, el Global report on trafficking in persons es elaborado por la Oficina de las Naciones Unidas contra la Droga y el Delito (UNODC). Su periodicidad es bienal y desde el 2009 se han producido 5 informes. Con respecto al tercer informe, el Global Slavery Index, es desarrollado por la organización no gubernamental Walk free foundation, que aboga por la erradicación de la esclavitud moderna en el mundo. La periodicidad de este informe inicialmente fue anual, pero en la actualidad es bienal y se han emitido 4 informes desde el 2013. Es importante mencionar que esta evaluación hace referencia al fenómeno de la trata de personas como "esclavitud moderna", definiendo dicho término como "aquellas situaciones de explotación que una persona no puede rechazar o abandonar debido a amenazas, violencia, coerción, engaño y / o abuso de poder" (Walk Free F., 2018, p.7). El documento aborda las finalidades de trata de personas, clasificándolas en dos grandes tipologías: (1) trabajos forzados en la economía privada, explotación sexual forzada y trabajos forzados impuestos por el Estado, y (2) matrimonios forzados. Con respecto a los objetivos de las mediciones, como se indica en la Tabla 2, básicamente consisten en determinar la magnitud del fenómeno en el mundo y en evaluar la acción estatal, principalmente enmarcada en la prevención, la protección y asistencia a víctimas y la judicialización correspondiente. Además, el Global

Tabla 2.

Dimensiones que abordan las mediciones globales

\begin{tabular}{|c|c|c|c|}
\hline & $\begin{array}{l}\text { Trafficking in persons report } \\
\text { (2018) }\end{array}$ & $\begin{array}{l}\text { Global report on trafficking in } \\
\text { Persons (2018) }\end{array}$ & Global Slavery Index (2018) \\
\hline Dimensiones & $\begin{array}{l}\text { - Cumplimiento de las normas } \\
\text { de protección de las víctimas } \\
\text { de la trata de personas: } \\
\text { normas mínimas para la } \\
\text { eliminación de la trata de } \\
\text { personas (Trafficking Victims } \\
\text { Protection Act - TVPA). }\end{array}$ & $\begin{array}{l}\text { - Perfil de las víctimas. } \\
\text { - Formas de explotación. } \\
\text { - Perfil de los delincuentes. } \\
\text { - Flujos del tráfico. } \\
\text { - Criminalización de la trata } \\
\text { de personas. }\end{array}$ & $\begin{array}{l}\text { - La prevalencia de la } \\
\text { esclavitud moderna en cada } \\
\text { país. } \\
\text { - Vulnerabilidad a la } \\
\text { esclavitud moderna. } \\
\text { - Respuestas del gobierno a la } \\
\text { esclavitud moderna. }\end{array}$ \\
\hline Fundamento & $\begin{array}{l}\text { Las TVPA, se fundamentan en } \\
\text { los compromisos adquiridos } \\
\text { en el Protocolo de Palermo. }\end{array}$ & $\begin{array}{l}\text { Visión general de los patrones } \\
\text { y flujos de la trata de } \\
\text { personas a nivel mundial, } \\
\text { regional y nacional, así como } \\
\text { el seguimiento y el análisis } \\
\text { de la trata de personas en } \\
\text { el contexto de un conflicto } \\
\text { armado }\end{array}$ & $\begin{array}{l}\text {-Se diseñaron variables para } \\
\text { predecir los casos de trabajo } \\
\text { forzado y matrimonio forzado. } \\
\text {-El modelo de vulnerabilidad } \\
\text { se basa en una puntuación de } \\
\text { riesgo para } 167 \text { países. } \\
\text {-La respuesta del Gobierno se } \\
\text { basó en aspectos normativos } \\
\text { y acciones programáticas de } \\
181 \text { países. }\end{array}$ \\
\hline \multirow[t]{2}{*}{$\begin{array}{l}\text { Ejemplo de } \\
\text { indicadores }\end{array}$} & $\begin{array}{l}\text { El gobierno prohíbe de forma } \\
\text { severa la trata de personas. }\end{array}$ & $\begin{array}{l}\text { Víctimas detectadas por } \\
\text { grupo de edad y sexo. }\end{array}$ & $\begin{array}{l}\text {-Inestabilidad política. } \\
\text {-Derechos políticos. } \\
\text {-Derechos de los } \\
\text { discapacitados. }\end{array}$ \\
\hline & $\begin{array}{l}\text { El gobierno del país debe } \\
\text { hacer esfuerzos serios y } \\
\text { sostenidos para eliminar } \\
\text { las formas graves de trata } \\
\text { de personas (acciones de } \\
\text { prevención, judicialización y } \\
\text { asistencia). }\end{array}$ & $\begin{array}{l}\text { Proporción de víctimas } \\
\text { detectadas por forma de } \\
\text { explotación }\end{array}$ & $\begin{array}{l}\text {-Impacto del terrorismo. } \\
\text {-Necesidades básicas } \\
\text { insatisfechas. }\end{array}$ \\
\hline
\end{tabular}

Fuente: elaboración propia 
Tabla 3.

Escalas de evaluación

\begin{tabular}{|c|c|c|}
\hline & $\begin{array}{l}\text { Trafficking in persons report } \\
(2018)\end{array}$ & Global Slavery Index (2018) \\
\hline $\begin{array}{l}\text { Fundamentos de } \\
\text { la escala }\end{array}$ & $\begin{array}{l}\text { Alcance de los esfuerzos de los } \\
\text { gobiernos para cumplir con los } \\
\text { estándares mínimos de TVPA } \\
\text { para la eliminación de la trata } \\
\text { de personas. }\end{array}$ & $\begin{array}{l}\text { Evaluación comparativa de las leyes, políticas, programas } \\
\text { y acciones. Posee } 104 \text { indicadores, de los cuales } 90 \text { son } \\
\text { denominados positivos y } 14 \text { negativos. Cada indicador es } \\
\text { evaluado de } 0 \text { a } 1 .\end{array}$ \\
\hline $\begin{array}{l}\text { Escalas para } \\
\text { niveles altos de } \\
\text { cumplimiento }\end{array}$ & $\begin{array}{l}\text { Tier 1: Los gobiernos de } \\
\text { los países que cumplen } \\
\text { plenamente las normas }\end{array}$ & $\begin{array}{l}\text { AAA: } 90 \text { a } 100 \text { puntos en los indicadores. El gobierno ha } \\
\text { implementado formas efectivas para responder a la esclavitud } \\
\text { moderna. }\end{array}$ \\
\hline
\end{tabular}
mínimas de TVPA para la eliminación de la trata de personas.

AA: 80 a 89.9 puntos en los indicadores. El gobierno ha implementado formas para responder a la esclavitud moderna.

A: 70 a 79.9 puntos en los indicadores. El gobierno ha implementado componentes claves para responder holísticamente a la trata.

Escalas para niveles medios de cumplimiento
Tier 2: Los gobiernos que no cumplen plenamente con los estándares mínimos de TVPA, pero están haciendo esfuerzos significativos para cumplirlos.

Lista de observación: no cumplen con los estándares mínimos del TVPA, pero están haciendo esfuerzos a pesar o gran número de casos. No se evidencian esfuerzos adicionales con respecto al año anterior. de que se evidencia aumento

BBB: 60 a 69.9 puntos en los indicadores. El gobierno ha implementado componentes claves para responder holísticamente a algunas formas de esclavitud moderna. Puede existir evidencia de víctimas deportadas.

BB: 50 a 59.9 puntos en los indicadores. El gobierno ha introducido respuestas para la esclavitud moderna incluyendo términos cortos de protección a víctimas. Puede existir evidencia de víctimas deportadas y facilitación a la esclavitud por parte de políticas o prácticas de gobierno.

B: 40 a 49.9 puntos en los indicadores. El gobierno ha introducido respuestas a la esclavitud moderna con limitado soporte a víctimas. Se criminalizan algunas formas de esclavitud. Evidencia de prácticas de deportación, criminalización de víctimas. Los servicios de asistencia son prestados por ONG con ayuda monetaria del país.

CCC: 30 a 39.9 puntos en los indicadores. El gobierno tiene una limitada respuesta a la esclavitud moderna. Evidencia de prácticas de deportación, criminalización de víctimas. Los servicios de asistencia son prestados por ONG con limitado soporte gubernamental.

están haciendo esfur significativos para cumplirlos. los países que no cumplen plenamente con los estándares mínimos de TVPA y no
Tier 3: Los gobiernos de niveles bajos de cumplimiento
CC:20 a 29.9 puntos en los indicadores. El gobierno tiene una limitada respuesta contra la esclavitud y un limitado marco penal. Hay evidencia de que el gobierno y las políticas facilitan la esclavitud. Los servicios de asistencia son prestados por ONG con limitado soporte gubernamental.

C: 10 a 19.9 puntos en los indicadores. La respuesta de gobierno es inadecuada con limitados o pocos servicios para las víctimas. La justicia criminal es débil y existe una débil coordinación institucional. Los servicios de asistencia son prestados por ONG con limitado soporte gubernamental.

D: 0 a 9.9 puntos en los indicadores. El gobierno tiene una respuesta totalmente inadecuada a la esclavitud moderna. Países con altos niveles de pobreza y conflicto interno.

Fuente: elaboración propia con base en revisión de informes. 
Slavery Index aborda otras dimensiones como la vulnerabilidad y los factores de riesgo.

Dos de los tres estudios (el TIP y el Global Slavery Index) se enmarcan dentro de sistemas de evaluación que permiten generar rankings de cumplimiento tendientes a aprobar o reprochar las acciones emprendidas por los países contra la trata de personas. Esto se traduce en escalas de medición que afectan positiva o negativamente la imagen internacional de los estados. Por ejemplo, el TIP posee una escala llamada Lista de vigilancia del nivel 2, en la que clasifica a aquellos gobiernos que no satisfacen plenamente las normas mínimas de la TVPA, pero que hacen esfuerzos considerables por satisfacerlas. El Global report on trafficking in Persons (2018) no presenta escala, ya que se enfoca en el análisis de la dinámica del delito. En la Tabla 3 se presentan en detalle las escalas de evaluación.

Estas mediciones han sido cuestionadas por varios expertos en el mundo (Kelley \& Simmons, 2015; Guth, Anderson, Kinnard, \& Tran, 2014). En el caso del TIP, se señala que la medición tiene un componente político y subjetivo (Kelley \& Simmons, 2015). Por su parte, el Global Slavery, en su informe 2016, presentó fuertes debilidades metodológicas y Dottridge (citado por Guth, et al., 2014, p. 19) se refirió a ello diciendo que "las cifras potencialmente inexactas también pueden generar respuestas igualmente inapropiadas" (p. 19).

De los resultados de Colombia en las tres mediciones, solo el TIP, presenta recomendaciones específicas para el país. Por ejemplo, se recomienda al Gobierno Nacional y a los gobiernos locales aumentar los servicios y fondos para las víctimas y proporcionar refugios; también mejorar la detección de las posibles víctimas entre los migrantes venezolanos, así como procesar y condenar enérgicamente los delitos de trata, incluido el trabajo forzoso (Dep. of State, 2018). Con respecto a las clasificaciones, la po-

Tabla 4.

Posicionamiento de Colombia en ranking mundial. sición de Colombia, como se observa en la Tabla 4 se ha determinado de acuerdo a las siguientes escalas:

Mientras en el ranking del Trafficking in persons report, el país se encuentra posicionado en un nivel alto de cumplimiento. En el Global Slavery Index, se observa un cumplimiento medio. Es decir que, a pesar de estar realizando esfuerzos para combatir el fenómeno, la asistencia a víctimas es limitada, entre otras debilidades. Estos resultados evidencian que, con respecto a las escalas, las definiciones del TIP resultan muy amplias (Gallagher \& Chuang, 2012; Frank, 2013).

Finalmente, deben enunciarse otros ejercicios de mediciones del fenómeno de la trata, que, si bien, no tienen el mismo impacto que los tres anteriormente mencionados, por no provenir de actores con tanta influencia, constituyen iniciativas importantes de ser conocidas. Por ejemplo, desde la academia se ha realizado un ejercicio de medición (Frank, 2013) en el que se desarrollan 55 variables codificadas para medir por año y país la ocurrencia de los tipos de trata y los esfuerzos gubernamentales en judicialización, protección y asistencia, y prevención. En esta medición, la información fue tomada en gran parte del TIP. Este documento resulta ser un informe general del avance de los países en cuanto a sus legislaciones y algunas dinámicas de la trata, que al no desagregar la información de manera descriptiva por país, su aporte a políticas nacionales y locales puede ser limitado.

La Organización Internacional de las Migraciones - OIM (2016), diseñó una propuesta de medición cuyo propósito es "establecer parámetros verificables y concretos para evaluar el nivel de cumplimiento del Protocolo para prevenir, reprimir y sancionar la trata de personas" (OIM, 2016, p.6). Este documento desarrolla unos indicadores de cumplimiento conforme al Protocolo de Palermo que son presentados en la Tabla 5.

\begin{tabular}{lll}
\hline & Trafficking in persons report (2018) & Global Slavery Index (GSI) (2018) \\
\hline Escala de posicionamiento & Tier 1(nivel 1) & B: 41.1 puntos en los indicadores \\
\hline Principales consideraciones & $\begin{array}{l}\text { El Gobierno de Colombia cumple } \\
\text { con los estándares mínimos para la } \\
\text { eliminación de la trata de personas. }\end{array}$ & $\begin{array}{l}\text { Se estimaron 131.000 víctimas en } \\
\text { Colombia. }\end{array}$
\end{tabular}

Fuente: elaboración propia con base en revisión documental. 
Tabla 5.

Indicadores

Niveles de Indicadores

\section{Número de \\ indicadores por \\ nivel \\ Escala de medición}

Indicadores generales: Aspectos como la tipificación del delito de la asignación de un estatus migratorio temporal

11 indicadores
Nivel alto de cumpimiento: se cumple en su totalidad.

o permanente especial para víctimas, la existencia de programas y servicios creados o adaptados para la asistencia y protección a personas víctimas, entre otros.

Indicadores intermedios: la tipificación de la tentativa; 8 indicadores Nivel medio de cumplimiento: se la tipificación de la complicidad; la tipificación de la cumple parcialmente.

organización o dirección para cometer; y las medidas para proteger la privacidad y la identidad de las personas, entre otros.

Indicadores específicos: cobertura de asistencia y protección a víctimas, existencia de sentencias contra 17 indicadores Nivel bajo de cumplimiento: no se cumple del todo. tratantes, asistencia y protección de VdT, educación y empleo, entre otras.

Fuente: elaboración propia con base en medición (OIM, 2016).

Este sistema de medición resulta de sencilla aplicación, sin embargo, sus resultados se limitan solo a la aplicabilidad del Protocolo, dejando de lado otros marcos normativos internacionales y los impactos de las medidas implementadas por los gobiernos. Esto último es una carencia común de la mayoría de las mediciones analizadas, ya que solo plantean formas de medir el desempeño y los resultados, pero no los impactos reales de las politicas contra la trata.

Finalmente, Young, Dreherb y Neumayerc (2012) proponen un índice que mide las políticas de lucha contra la trata para 180 países en el período 2000-2010 y si bien toma en cuenta el Protocolo de Palermo, se interesa también por analizar qué determina el cumplimiento de las políticas antitrata, incorporando otras variables. Los autores analizan cómo en países con bajos niveles de corrupción y alto respeto por los derechos de las mujeres, aumenta el cumplimiento de las politicas antitrata. En la Tabla 6 se presentan las tres dimensiones principales de las políticas contra la trata: enjuiciamiento, protección y prevención, que mide este índice. La escala de cumplimiento utilizada para valorar a cada estado es de 5 a 1 (siendo 5 cumplimiento total y 1 el no clumplimiento).

\section{Propuesta de medición a nivel regional: el caso de Centroamérica}

La medición de la respuesta estatal frente a la trata de personas en la región Centroamericana integrada por Belice, Panamá, Nicaragua, El Salvador, Guatemala, Costa Rica y Honduras

Tabla 6.

Dimensiones y criterios de observación

\begin{tabular}{ll}
\hline Dimensión & Criterios de observación \\
\hline Persecución & $\begin{array}{l}\text { El país cuenta con medidas legislativas y de otra índole para establecer delitos penales por } \\
\text { trata de personas de acuerdo con la definición proporcionada por el Protocolo contra la trata } \\
\text { de personas; y si tales medidas legislativas y de otra índole se aplican de manera apropiada y } \\
\text { efectiva. }\end{array}$ \\
\hline Protección & $\begin{array}{l}\text { Si el país protege los derechos humanos de las víctimas de la trata; los identifica; y le proporciona } \\
\text { recuperación física, psicológica y social a las víctimas de la trata a través de medidas legislativas } \\
\end{array}$ \\
& y otras medidas. \\
\hline Prevención & El país establece y practica políticas, programas y otras medidas integrales para prevenir y \\
& combatir la trata de personas \\
\hline
\end{tabular}

Fuente: elaboración propia. 
Tabla 7.

Matriz de indicadores: diagnóstico y seguimiento de la trata de personas en Centroamérica.

\begin{tabular}{|c|c|c|c|c|}
\hline \multirow[t]{2}{*}{ Dimensiones } & \multirow[t]{2}{*}{ Subdimensiones } & \multicolumn{3}{|l|}{ Indicadores } \\
\hline & & estructurales $^{1}$ & Proceso $^{2}$ & Resultados $^{3}$ \\
\hline \multirow[t]{4}{*}{ Jurídica } & $\begin{array}{l}\text { Marco normativo } \\
\text { internacional. }\end{array}$ & 4 & 8 & 12 \\
\hline & $\begin{array}{l}\text { Ley nacional contra la trata de } \\
\text { personas. }\end{array}$ & 3 & 4 & 10 \\
\hline & $\begin{array}{l}\text { Normativa nacional vinculada } \\
\text { a la trata de personas. }\end{array}$ & 2 & 3 & 7 \\
\hline & $\begin{array}{l}\text { Política pública contra la trata } \\
\text { de personas. }\end{array}$ & 2 & 2 & 3 \\
\hline \multirow[t]{6}{*}{ Institucional } & $\begin{array}{l}\text { Órgano rector en materia de } \\
\text { trata de personas. }\end{array}$ & 3 & 5 & 10 \\
\hline & $\begin{array}{l}\text { Fortalecimiento de las } \\
\text { capacidades estatales. }\end{array}$ & 2 & 2 & 4 \\
\hline & $\begin{array}{l}\text { Participación de actores no } \\
\text { gubernamentales. }\end{array}$ & 3 & 4 & 7 \\
\hline & $\begin{array}{l}\text { Coordinación } \\
\text { interinstitucional. }\end{array}$ & 2 & 2 & 3 \\
\hline & Cooperación internacional. & 2 & 3 & 4 \\
\hline & $\begin{array}{l}\text { Intervención de organismos } \\
\text { regionales. }\end{array}$ & 2 & 4 & 4 \\
\hline \multirow[t]{2}{*}{$\begin{array}{l}\text { Económica y } \\
\text { financiera }\end{array}$} & $\begin{array}{l}\text { Fuentes de financiación para } \\
\text { combatir la trata de personas. }\end{array}$ & 5 & 8 & 18 \\
\hline & $\begin{array}{l}\text { Recursos económicos } \\
\text { requeridos para implementar } \\
\text { la Ley Nacional. }\end{array}$ & 2 & 2 & 10 \\
\hline \multirow[t]{5}{*}{ Social } & $\begin{array}{l}\text { Identificación de víctimas de } \\
\text { la trata de personas. }\end{array}$ & 1 & 2 & 2 \\
\hline & $\begin{array}{l}\text { Protección a víctimas y } \\
\text { testigos. }\end{array}$ & 3 & 4 & 7 \\
\hline & $\begin{array}{l}\text { Asistencia a víctimas de la } \\
\text { trata de personas. }\end{array}$ & 2 & 4 & 9 \\
\hline & Seguridad Migratoria. & 4 & 5 & 8 \\
\hline & $\begin{array}{l}\text { Reparación de los daños } \\
\text { ocasionados por el delito de } \\
\text { trata de personas. }\end{array}$ & 1 & 3 & 3 \\
\hline Cultural & $\begin{array}{l}\text { Sensibilización y } \\
\text { concientización. }\end{array}$ & 2 & 4 & 7 \\
\hline \multirow[t]{2}{*}{ Total indicadores } & & 45 & 69 & 128 \\
\hline & 242 & & & \\
\hline
\end{tabular}

Fuente: elaboración propia

1 Reflejan la estipulación de los instrumentos jurídicos y la existencia de mecanismos institucionales básicos para implementar las medidas requeridas en materia de trata de personas. Revelan, por tanto, cómo se organiza el aparato institucional y el sistema jurídico del Estado.

2 Miden la calidad y la magnitud de los esfuerzos del Estado para implementar las directrices y lineamientos establecidos en términos del alcance, la cobertura y el contenido de las estrategias, políticas, planes, programas u otras actividades e intervenciones específicas derivadas del Protocolo de Palermo y establecidas, en su caso, en la Ley Nacional Contra la Trata de Personas.

3 Reflejan el estado de realización de los lineamientos del Protocolo de Palermo y de la legislación nacional contra la trata de personas. Miden el impacto real de las estrategias, programas e intervenciones del Estado desde la prevención hasta la sanción del delito. 
constituye el objeto de interés de la matriz de indicadores elaborada por el Instituto de Estudios Estratégicos y Políticas Públicas (IEEPP) de Nicaragua. Dicha respuesta en un contexto regional, si bien es monitoreada principalmente a partir de los lineamientos del Protocolo de Palermo, tiene en cuenta también la adecuación normativa que los países hayan realizado, conforme a la Convención Americana sobre Derechos Humanos y la Convención Interamericana para Prevenir, Sancionar y Erradicar la Violencia contra las Mujeres y el Convenio Centroamericano para la Protección de Víctimas, Testigos, Peritos y demás sujetos que intervienen en la investigación y en el Proceso Penal, particularmente en la narcoactividad y delincuencia organizada.

Este instrumento de medición está diseñado con el propósito de que los funcionarios y funcionarias con competencias en el abordaje de la trata de personas puedan por sí mismos realizar una auditoría social interna y que se genere una comprensión acerca de que la revisión y medición periódica de los resultados de la intervención normativa debe ser una las funciones básicas de las instancias encargadas de su regulación, a fin de garantizar una legislación de calidad (IEEPP, 2015, p.7-8).

La matriz define cinco dimensiones que determinan el cumplimiento y la aplicabilidad de las leyes sobre trata de personas, a saber, (1) jurídica, (2) institucional, (3) económica y financiera, (4) social y (5) cultural, las cuales se dividen a su vez en 18 subdimensiones, medidas a través de 242 indicadores de tres tipos: estructurales (45), de proceso (69) y de resultado (128), como se indica en la Tabla 7. El IEEPP señala que los indicadores de resultado suelen ser difíciles de medir dado que no todos los países cuentan con la información suficiente (IEEPP, 2015, p.10).

El IEEPP (2015) señala que al aplicar la matriz mediante ejercicios de actualización periódica

Tabla 8.

Medición de los indicadores

\begin{tabular}{lll}
\hline Escala & Puntaje & Nivel de avance \\
\hline $1-1.49$ & 1 & Nulo o insuficiente \\
\hline $1.5-2.49$ & 2 & Mediano \\
\hline $2.5-3.49$ & 3 & Bueno \\
\hline $3.5-4$ & 4 & Muy bueno \\
\hline
\end{tabular}

Fuente: elaboración propia es posible medir los avances o retrocesos ocurridos en los estados en materia de trata de personas, lo que permite identificar también los vacíos y ventajas comparativas entre los países de la región.

Para demostrar lo anterior, el IEEPP hizo una aplicación de la matriz en un análisis comparado de Costa Rica, Honduras y Nicaragua, calificando sus avances en cuatro niveles: nulo o insuficiente, mediano, bueno y muy bueno. En los casos en los que un indicador estructural tiene varios indicadores de proceso se establece un promedio entre 1 y 4 apelando a la escala que aparece en la Tabla 8.

\section{Indicadores para el monitoreo de la respuesta de los estados en el abordaje de la trata de personas a niveles global, regional, nacional y subnacional}

En esta sección se presenta un breve análisis de 396 indicadores contenidos en 7 propuestas de medición con distintas coberturas geográficas y con diversidad en el perfil de los actores que las proponen. Estos últimos pueden clasificarse en cinco categorías: (1) Gubernamental (Ministerio de Justicia y Seguridad Pública del Salvador, 2016; Mesa Intersectorial sobre trata de personas, 2015, (2) Organismo supranacional (OIM, 2016), (3) Académico (Bocanument-Arvelaez, 2012), (4) No gubernamental (IEEPP, 2014) y (5) Gubernamental con apoyo de Organismo supranacional (Procuraduría General de la Nación, OIM \& UNODC, 2018; Ministerio del Interior \& OIM, 2012). En el Anexo 1 está disponible la compilación de los indicadores.

Los indicadores fueron clasificados en las siete dimensiones señaladas en la Tabla 9, las cuales se establecieron en relación con los principios y directrices recomendados sobre derechos humanos y trata de personas (ACNUDH, 2010) y con los ejes de la estrategia nacional de lucha contra la trata de 
Tabla 9.

Dimensiones $e$ indicadores

\begin{tabular}{ll}
\hline Dimensión & Número de indicadores \\
\hline 1) Indicadores de marcos normativos. & 33 \\
\hline 2) Indicadores de detección, identificación y dinámica de la trata de personas . & 56 \\
\hline 3) Indicadores de Prevención de la trata de personas. & 40 \\
\hline 4) Indicadores de protección y asistencia. & 107 \\
\hline 5) Indicadores de penalización, sanción y reparación. & 51 \\
\hline 6) Indicadores de coordinación, cooperación, sostenibilidad y acceso a recursos. & 98 \\
\hline 7) Indicadores de generación y gestión del conocimiento. & 11 \\
\hline Total & 396 \\
\hline
\end{tabular}

Fuente: elaboración propia

personas en Colombia 2012-2018.

\subsection{Indicadores de marcos normativos}

Esta dimensión abarca todos los indicadores que dan cuenta de la inclusión de las diferentes normatividades contra la trata en los sistemas jurídicos nacionales. Se incluyeron 33 indicadores que comprenden el 8\% del total de los indicadores analizados.

Dentro de los indicadores comúnmente usados en las mediciones con respecto a marcos normativos, se encuentran aquellos relacionados con la inclusión del Protocolo de Palermo en las normativas nacionales. Este tipo de indicadores suele ser de cumplimiento, en cuanto a la creación de leyes que tipifiquen el delito de trata y asistan a las víctimas. Estos indicadores sirven principalmente para mediciones comparativas entre países. Por ello, la mayoría de indicadores en este sentido, provenían del documento de medición de Centroamérica (Instituto de Estudios Estratégicos y Políticas Públicas, 2015). También se encuentran los indicadores que evalúan la existencia de políticas públicas nacionales para combatir el delito.

Otros indicadores propuestos en las mediciones tienen que ver con la aprobación de tratados internacionales diferentes al Protocolo que protegen a las poblaciones vulnerables y que enmarcan fenómenos en conexidad con la trata de personas, como el Pacto Internacional de Derechos Civiles y Políticos, la Convención sobre los Derechos del Niño, el Protocolo Facultativo concerniente a la venta de niños, la Convención de Belém do Pará (que considera la trata de personas como una manifestación de violencia contra la mujer), entre otras.
Es llamativo un indicador planteado por el documento de la OIM (2016), que refiere "la obligación de transportistas de asegurarse de que cada pasajero cuente con la respectiva documentación de viaje e identidad está regulada y existe una sanción en caso contrario". Este es un indicador que suele ser poco frecuente en los análisis y mediciones contra la trata de personas.

También dentro de los indicadores de marcos normativos se encuentran aquellos que refieren a la adopción de políticas públicas para combatir el delito. Por ejemplo, “aprobado el Plan Estratégico Nacional contra la Trata de Personas”, "elaborada y aprobada la política pública o el plan nacional contra la trata de personas" (Instituto de Estudios Estratégicos y Políticas Públicas, 2015); entre otras.

Finalmente, dentro de la revisión realizada se encuentra que ninguno de los indicadores de marco normativo apunta al denominado análisis de impacto normativo (AIN). Este tipo de análisis hace parte de las recomendaciones a nivel global propuestas por la Organización para la Cooperación y el Desarrollo Económicos (OCDE) para la creación de normas. En este sentido, en el caso del Gobierno colombiano, a partir del documento Conpes 3816 de 2014, se insta a diseñar leyes basadas en dichos procedimientos técnicos. El AIN, básicamente es una metodología para el diseño e implementación de leyes y es definido por la OCDE, como:

Una herramienta que ayuda al proceso decisorio porque sistemáticamente examina los impactos potenciales de las acciones gubernamentales, haciendo preguntas sobre costos y beneficios, sobre cuán 
efectiva será la acción gubernamental en alcanzar los objetivos y si hay otras alternativas viables para los gobiernos. Como un proceso decisorio, el AIN está integrado a sistemas de consulta, desarrollo de políticas y procesos regulatorios dentro del gobierno, sirviendo para comunicar y dar información ex ante sobre los efectos esperados de las propuestas gubernamentales y ex post en la medida en que ayuda a los gobiernos a evaluar las regulaciones existentes. (OECD, 2009, citado por el Departamento Nacional de Planeación, 2015, p. 7)

De acuerdo con esta tendencia y recomendación de las organizaciones internacionales, se hace necesario que la trata de personas pueda enmarcarse también en estas metodologías de AIN. Por ejemplo, implementar políticas públicas contra la trata de personas podría basarse en las herramientas que comprende la AIN, como la medición del cumplimiento o no de las leyes, los efectos de la tipificación en la judicialización efectiva, entre otros.

\subsection{Indicadores de detección, identificación y dinámica}

En la dimensión de indicadores de detección, identificación y dinámica de la trata de personas, se encuentra el $14 \%$ del total de indicadores. En estos, se presentan dos tipos de indicadores, por un lado, los que caracterizan la dinámica del delito, como modalidad de la trata, rutas y redes de explotación; perfil de las víctimas; entre otros. Por otra parte, se encuentran aquellos indicadores que abarcan factores de vulnerabilidad que pueden ser indicios para detectar víctimas de trata de personas. Por ejemplo, "número de adolescentes y jóvenes embarazadas o que ya son madres en el departamento", "número de personas que ejercen mendicidad en lugar público o abierto al público en el departamento"; "número de empleados y empleadas de servicio doméstico en el departamento" (OIM, 2012).

Con respecto a estos últimos, que se encuentran en el "Manual para la formulación de Políticas Públicas de Lucha Contra la Trata de Personas y el diseño y ejecución de Planes de Acción Departamentales, Distritales y/o Municipales" de la OIM, pueden resultar poco operativos en la práctica. Dado que, algunos de ellos no se analizan con base en la relación que puedan tener con el fenómeno de la trata. Igualmente, de acuerdo a dicho manual, esos indicadores son solicitados a los Comités de trata en Colombia, quienes en muchas ocasiones no cuentan con esta información, puesto que solo manejan las cifras del delito de trata de personas y no de otros fenómenos como es el caso del embarazo adolescente o el número de viajeros nacionales e internacionales que llegaron al departamento.

Llaman la atención los indicadores propuestos en esta dimensión por Bocanument (2012) en relación con fenómenos asociados con la trata de personas. Por ejemplo, la relación de variables "Número de víctimas de la explotación para pornografía / el total de víctimas de trata de personas identificado", "número de denuncias recibidas por explotación pornográfica / el total de denuncias recibidos por trata de personas" (Bocanument-Arvelaez, 2012). Estas mediciones, relacionando distintas variables, pueden aportar importantes análisis a la lucha contra la trata de personas. Sin embargo, a las instituciones públicas puede resultarles complejo realizar dichas mediciones dada la falta de información consolidada que pueden tener.

Por último, se evidenció la inexistencia de indicadores orientados a determinar el perfil de los victimarios. Este aspecto, también resulta importante para analizar las dinámicas del delito, las formas de captación y las tendencias en cuanto a perfiles criminales.

\section{Indicadores de prevención}

Los indicadores en esta dimensión están orientados principalmente a la medición de resultados en términos de número de campañas, actividades y estrategias que prevengan la trata de personas.

Otros indicadores buscan medir la frecuencia de uso de las líneas telefónicas de atención contra la trata, el tipo de capacitación que reciben sus operadores (Bocanument-Arvelaez, 2012) y la creación e interacción de páginas web oficiales de las instituciones que hacen parte de las instituciones de la Mesa Intersectorial para el caso de Chile, y el Instituto de Estudios Estratégicos y Políticas Públicas para Centroamérica.

Por otro lado, también se plantean indicadores sobre si medios de comunicación tienen conocimiento sobre la temática y si difunden mensajes de prevención sin ánimo de lucro (Bocanument-Arvelaez, 2012).

También, se presentan tres indicadores en tres documentos, que apuntan a medir directamente las acciones (Mesa Intersectorial sobre Trata de 
Personas, 2015) o estrategias dirigidas a educación y promoción de derechos humanos (Procuraduría General de la Nación et al, 2018), y a la atención de factores de vulnerabilidad que desestimulen la demanda (OIM, 2016).

De manera particular se presentan indicadores que buscan medir cuántas de estas acciones vinculan a otros actores, como las Organizaciones de la Sociedad Civil, la academia y el sector privado, como el "número de estrategias implementadas para la generación de procesos de responsabilidad empresarial encaminados a la prevención de la trata de personas" (Procuraduría General de la Nación et al., 2018). Solo el Instituto de Estudios Estratégicos y Políticas Públicas (2015) reconoce la importancia de la vinculación de las universidades en materia de prevención, proponiendo un indicador con el que mide que los gobiernos centroamericanos hayan creado e implementado un currículo universitario nacional con contenidos sobre la trata de personas.

\section{Indicadores de protección y asistencia}

Esta dimensión representa el 27\% del total de indicadores referidos principalmente a la garantía de la asistencia inmediata y mediata en términos de asesoría legal, atención médica, psicológica y psiquiátrica, reintegración al sistema educativo y laboral, alojamiento temporal o permanente.

Los indicadores que destacamos en esta dimensión están referidos a la existencia de un programa integral de asistencia a las víctimas nacionales (Bocanument-Arvelaez, 2012) y la actuación en casos de repatriación de víctimas extranjeras, así como la atención a los dependientes y familiares de las víctimas (IEEPP, 2014; OIM, 2016).

El IEEPP (2014) propone también indicadores de multas y sanciones frente al manejo inadecuado de la confidencialidad de la identidad de la víctima y de la información suministrada por ella en perspectiva de prevenir la revictimización tanto en la atención por parte de los funcionarios y funcionarias, como en la recaptación por parte de los tratantes (OIM, 2016).

Una vez se presta la asistencia a las víctimas de trata de personas externa e interna, el Ministerio del Interior \& OIM (2012), proponen un indicador que mide el número total de casos que tuvieron seguimiento por parte de las instituciones del comité de lucha contra la trata de personas en los municipios y departamentos. El seguimiento es una de las debilidades del proceso de asistencia; en un estudio realizado por Aceros, J.C., VargasParra, J. \& Reyes, J. (2017), lograron documentar a través de la reconstrucción de casos, que una vez que una institución que forma parte del comité de lucha contra la trata, activa la denominada ruta de atención a las víctimas, esta les ofrece algún tipo de asesoría o servicio de acuerdo a su competencia e inmediatamente las deriva al siguiente eslabón de la ruta y posteriormente "no se adelantan acciones de seguimiento una vez que una institución ha cumplido su parte en el proceso"(p.45).

En la propuesta de la Mesa Intersectorial sobre Trata de Personas (2015) se evidencia un interés por la autoevaluación, planteando la medición a través de un informe de brechas que compara a los servicios prestados a las víctimas con lo estipulado por el Protocolo de Palermo. En Colombia, la Procuraduría General de la Nación et al. (2018), en cumplimiento de su función de vigilancia sobre los funcionarios y las funcionarias con competencias en el abordaje de la trata de persona, también propone indicadores relacionados con la presentación de informes trimestrales en los que se relacionen los servicios prestados a las víctimas en la asistencia inmediata y mediata.

Por otra parte, la Procuraduría General de la Nación et al. (2018), señala un indicador muy importante relacionado con la capacitación del personal con competencia en trata de personas, específicamente en materia de asistencia y protección a las víctimas. Este es un tema sensible dado que la formación impartida a funcionarios y funcionarias es sobre todo teórica y suele enfatizar principalmente en los aspectos legales de la asistencia, descuidando el aprendizaje de competencias prácticas que los habiliten para saber cómo reaccionar y qué acciones emprender cuando una víctima de trata de personas está frente a ellos en sus despachos (Vargas, Aceros, Reyes y Urón, 2018, p.7).

\section{Indicadores de penalización, sanción y reparación}

El 13\% de los indicadores se enmarcaron en la dimensión de penalización, sanción y reparación. En esta se encuentran, mayoritariamente, indicadores que permiten determinar el número de sentencias, de acusados, de investigaciones, condenados, entre otros aspectos. En menor medida, se encuentran 
indicadores orientados a evaluar lo concerniente a la reparación de víctimas. Algunos de ellos, por ejemplo, buscan determinar si "las personas sobrevivientes a la trata han sido indemnizadas o recibido un monto económico por los daños sufridos" (OIM, 2016, p. 14). Los indicadores de este tipo resultan bastante limitados pues no hay algún indicador que permita determinar los montos en los que oscilan las reparaciones recibidas por las víctimas como indemnización.

En esta dimensión también se encuentran algunos indicadores relacionados con la formación y capacitación de los organismos de investigación $\mathrm{y}$ judicialización $\mathrm{y}$ acciones en materia de implementación de protocolos de investigación.

Con respecto a esta dimensión, se evidencia que los indicadores suelen ser limitados en cuanto a las acciones que miden. En este aspecto se considera que, por ejemplo, las debilidades en la judicialización se pueden medir a través de las sentencias. Por ejemplo, indicadores que busquen determinar cuáles son las condenas que se han dado a los tratantes y cuáles son las debilidades en investigación encontradas en las sentencias, entre otros aspectos.

Asimismo, en cuanto a indicadores que midan el desempeño de la justicia, se hace necesario que se incluyan indicadores que analicen relaciones entre variables. Una de estas, puede ser la relación entre número de investigaciones ingresadas por año y número de sentencias proferidas. Indicadores como estos, permitirian medir el desempeño y operatividad de los procesos investigativos y de justicia.

\section{Indicadores de coordinación, cooperación, sostenibilidad y acceso a recursos}

En esta dimensión se hallan indicadores que miden la inclusión del abordaje de la trata de personas en los instrumentos de planeación, tales como el plan de desarrollo, el Plan Operativo Anual de Inversiones y el presupuesto (Ministerio del Interior \& OIM, 2012). Se proponen también monitorear específicamente el presupuesto aprobado por los departamentos para el funcionamiento del comité de lucha contra la trata de personas y para cada una de las actividades en materia de prevención y asistencia y protección e investigación y judicialización en el tema de trata de personas.
En materia de coordinación el IEEPP (2016), en Centroamérica, reconoce al sector privado y a las organizaciones de la sociedad civil como actores clave en la conformación del ente rector interinstitucional en materia de trata de personas, señalando en uno de sus indicadores que las OSC formen parte, con voz y voto y que participan en la elaboración e implementación del plan nacional/ política pública para combatirla. Al respecto, en Colombia, la Procuraduría General de la Nación et al. (2018) se propone medir el número de espacios de discusión y concertación con las Organizaciones de la Sociedad Civil.

El IEEPP (2016) propone también un indicador de monitoreo para las Organizaciones no gubernamentales, respecto de la administración adecuada de los albergues para las víctimas. En materia de cooperación, los indicadores del IEEPP (2016), plantean reuniones regionales, foros multilaterales y la elaboración y divulgación de guías y directrices sobre las acciones que los Estados centroamericanos deben emprender para combatir la trata de personas y encuentran en la pertenencia a la Asociación Iberoamericana de Ministerios Públicos (AIAMP) un incentivo a la cooperación y la asistencia jurídica mutua

\section{Indicadores de generación y gestión del conocimiento}

De los 396 indicadores analizados tan solo se identificaron 11 en la categoría de generación y gestión del conocimiento, de los cuales 7 hacen referencia a elaboración de documentos tales como investigaciones académicas, investigaciones, informes y diagnósticos, ya sea para determinar la situación de las diferentes finalidades de trata, o para dar seguimiento a los compromisos internacionales de manera oportuna y veraz (IEEPP, 2015). Singularmente, se propone en los indicadores restantes de esta categoría que se promueva un sistema integrado de homogenización de estadísticas, así como los mecanismos de información para la ciudadanía.

Además, se plantea una medición sobre el "número de buenas prácticas detectadas en el análisis de casos" dicho indicador responde al Plan Nacional contra la Trata de Personas elaborado por la Mesa Intersectorial sobre Trata de Personas de Chile (2015). Lo anterior, permite que se amplíe la responsabilidad de la generación y gestión del 
conocimiento a la función pública, teniendo en cuenta que usualmente es a la academia a quién se responsabiliza por esta dimensión.

Finalmente, desde la Procuraduría General de la Nación et al. (2018) se propone la creación y administración de un observatorio sobre el Delito de la trata de personas, que permita recopilar, sistematizar y analizar la información relativa a este delito tanto a nivel internacional, nacional y descentralizado del conocimiento.

\section{Conclusiones}

La revisión de literatura permitió identificar que el interés por la medición de la respuesta de los estados en el abordaje de la trata de personas ha convocado a diversos actores, gubernamentales, organizaciones no gubernamentales, organismos supranacionales y académicos a proponer modelos de evaluación a nivel mundial, regional y subnacional. A partir de los hallazgos, se señalan primero las metodologías y las escalas de medición halladas a nivel global y regional y después se consolida un conjunto de 396 indicadores.

Con respecto a las escalas de medición contenidas en las mediciones de nivel global y regional, 5 de ellas establecen rankings a través de los cuales los países reciben una calificación, determinada por indicadores que observan el cumplimiento principalmente de los compromisos adquiridos con la ratificación del Protocolo de Palermo. La observación de las disposiciones normativas regionales en la materia, de otros tratados internacionales y de otras variables como la corrupción y el respeto por los derechos de las mujeres que, según Young, Dreherb y Neumayerc (2012) aumentan el cumplimiento de las políticas contra la trata, es mínima.

Las escalas de medición otorgan a cada uno de los países, frente a la comunidad internacional, un estatus de alto, medio o bajo cumplimiento como en el caso de la medición de OIM (2016) y en ese mismo orden el Trafficking in Persons establece calificaciones de 1,2 y 3 , calificando con 1 a los gobiernos de los países que cumplen plenamente las normas minimas de TVPA para la eliminación de la trata. Por su parte el Global Slavery Index califica con A, B, C y D y dentro de cada uno de estos niveles establece unos subniveles. Así, por ejemplo, los países con más alto nivel de cumplimiento son $\mathrm{AAA}$; los que no tienen una respuesta adecuada o limitada son $\mathrm{C}$ y aquellos que tienen una respuesta totalmente inadecuada a la esclavitud moderna son D. Finalmente a nivel global, Young, Dreherb y Neumayerc (2012) proponen una escala de 5 (cumplimiento total) a 1 (no cumplimiento) en las tres dimensiones principales de las políticas contra la trata: enjuiciamiento, protección y prevención. A nivel regional, el único caso hallado en la literatura fue el centroamericano, que establece un promedio entre 1 y,4 traducida en una escala de nivel de avance nulo, mediano, bueno y muy bueno.

En materia de indicadores, estos fueron clasificados en torno a siete dimensiones: (1) marcos normativos, (2) detección, identificación y dinámica de la trata de personas, (3) prevención de la trata de personas, (4) protección y asistencia, (5) penalización, sanción y reparación, (6) coordinación, cooperación, sostenibilidad y acceso a recursos, (7) generación y gestión del conocimiento. Esta última dimensión contiene solo el 3\% del total de los indicadores mientras que las dimensiones 4 y 6 concentran el mayor porcentaje equivalente al 74,49\%.

El ejercicio de consolidación de estos indicadores permitió evidenciar la comprensión que los respectivos autores hacen del fenómeno de la trata de personas y la importancia que cada una de las dimensiones señaladas tiene en su propuesta de medición. Un análisis de ese tipo desborda los objetivos del presente trabajo. No obstante, se señalan cinco aspectos:

1. La voz de las víctimas en dichas propuestas, pues, si bien algunas de ellas incorporan principios de derechos humanos en su atención, ninguna de las mediciones analizadas contempla indicadores que den cuenta del nivel de satisfacción de las víctimas con los servicios prestados en el dispositivo institucional dispuesto para su atención, lo cual sería fundamental para fortalecer los procesos $y$ garantizar la restitución efectiva de sus derechos y reconocería en ella su agencia.

2. El impacto de las acciones de prevención no es objeto de medición, dado que estas se enfocan en presentar resultados y cumplimientos de los planes a los que responden los indicadores encontrados y no se evidencia la evaluación de acciones orientadas a combatir la demanda que nutre las dinámicas de la trata de personas.

3. En cuanto a los indicadores de marco normativo, 
sería importante analizar el posible uso de herramientas de las metodologías de análisis de impacto normativo (AIN) para diseñar las políticas públicas contra la trata de personas y medir el impacto de estas.

4. La gestión del conocimiento es un aspecto con poco interés de ser observado y es determinante en la implementación y evaluación de las políticas públicas para el abordaje de la trata de personas, dada la valía de la experiencia de las instituciones y sus funcionarios y funcionarias en la prevención, atención, investigación y judicialización de los casos de trata de personas.

5. La inclusión de indicadores que determinen el abordaje de la trata de personas en la planeación del desarrollo es un acierto en una de las propuestas analizadas, dado que son fundamentales para que la política pública se concrete en los niveles municipal y departamental. En consecuencia, se fortalecería la gestión pública en esta materia a través de la rendición de cuentas y la veeduría ciudadana.

Este trabajo aporta un insumo fundamental para los interesados en el diseño de estrategias de seguimiento, monitoreo y evaluación de la respuesta de los gobiernos nacionales y subnacionales en el abordaje de la trata de personas. Las mediciones globales muestran la importancia del establecimiento de escalas de medición de dicha respuesta y el impacto que genera en los gobiernos. Se hace necesario entonces definir un sistema de indicadores apropiados al contexto de nuestros países y una escala de medición que permita comparar el nivel de avance entre los países de la región y entre niveles subnacionales al interior de los países.

\section{Referencias}

Aceros, J. C., Vargas-Parra, J., \& Reyes, J. (2017). Trayectorias territoriales de la asistencia a víctimas de trata de personas. Análisis cualitativo de la perspectiva de los actores institucionales en Santander, Colombia. Revista Criminalidad, 59(2), 33-48. Obtenido de https://www.policia. gov.co/revista/volumen-59-no-2

ACNUDH. (2010). Principios y Directrices recomendados sobre los derechos humanos y la trata de personas. Nueva York y Ginebra: Naciones Unidas.

Alianza Libres Sin Violencia. (2015). Sistema de indicadores para medir percepciones ciudadanas sobre la respuesta institucional contra la violencia hacia la mujer y la trata y tráfico de personas. Bolivia: Ciudadanía.

Añorve, D. (2016). Más allá del poder suave, del poder duro y del poder inteligente:la resiliencia ecológica y humana como fundamentos del poder. Revista de Relaciones Internacionales de la UNAM (125), 35-60. Obtenido de http://www.revistas. unam.mx/index.php/rri/article/view/58597

Bales, K., \& Datta, M. (2015). Slavery as Social Institution. International Encyclopedia of the Social \& Behavioral Sciences, 43-48. doi:10.1016/B978-008-097086-8.32133-X

Bocanument-Arvelaez, M. (2012). Política Pública Sobre Trata de Personas en Medellín-Colombia. Alemania: Editorial Académica Española.

Brewster, B., Ingle, T., \& Rankin, G. (2014). Crawling Open-Source Data for indicators of Human Trafficking. IEEE/ACM 7th International Conference on Utility and Cloud Computing (págs. 714-719). Londres: IEEE. doi:10.1109/ UCC.2014.116

Congreso de Colombia. (2005). LEY N 985. Obtenido de Ministerio del Interior. Obtenido de https:// www.mininterior.gov.co/la-institucion/normatividad/ley-985-del-2005

Davis, K. \& Kingsbury, B. (12 de octubre de 2014). Indicadores como intervenciones: obstáculos y expectativas al apoyar iniciativas de desarrollo. Revista Colombiana de Derecho Internacional, 12(25), 473-542. doi:http://dx.doi.org/10.11144/Javeriana.il14-25.icio.

Departamento Nacional de Planeación. (2015). Guía Metodológica de Análisis de Impacto Normativo. Obtenido de: https://www.dnp.gov.co/programas/Mejora\%20Regulatoria/Paginas/Documentos.aspx

Department of State. (2018). Trafficking in person report. Washington, D.C.: Department of State. Obtenido de: https://www.state.gov/j/tip/rls/tiprpt/

Dirección de Información y Análisis. (2016). Fichas de indicadores para el sistema nacional de información sobre el delito de trata de personas en el Salvador. Obtenido de: Ministerio de Justicia y Seguridad Pública del Salvador: http://www. seguridad.gob.sv/dia/download/1817/

Espacios de Mujer. (2018). III Balance de la implementación de las políticas anti-trata en Colombia. Colombia: Espacios de Mujer. Obtenido de: http://www.espaciosdemujer.org/wp-content/uploads/COMUNICADO_III-BALANCE_ EDM-compressed.pdf

Frank, R. (2013). Human Trafficking Indicators, 20002011: A New Dataset. Sydney: University of Sydney. Obtenido de: http://ssrn.com/abstract $=2314157$ 
Gallagher, A. T., \& Chuang, J. (2012). The use of Indicators to Measure Goverment Responses to Human Trafficking. En K. Davis, A. Fisher, B. kingsbury, \& S. Engle, Governance by indicators (pp.317-343). Oxford: Oxford University.

Guth, A., Anderson, R., Kinnard, K., \& Tran, H. (2014). Proper methodology and methods of collecting and analyzing slavery data: An examination of the global slavery index. Social Inclusion, 2(4), 14-22. doi:http://dx.doi.org/10.17645/ si.v2i4.195

Hoyos, C. (2000). Un modelo para investigación documental: guía teórico práctica sobre construcción de Estados del Arte con importantes reflexiones sobre la investigación. Medellín: Señal Editora. Obtenido de: https://es.scribd.com/ doc/16281901/UN-MODELO-PARA-INVESTIGACION-DOCUMENTAL-29-04-08

Ibanez, M., \& Suthers, D. (2014). Detection of Domestic Human Trafficking Indicators and Movement Trends Using Content Available on Open Internet Sources. 47th Hawaii International Conference on System Science (pp.1556-1565). Hawaii: IEEE. doi:10.1109/HICSS.2014.200

Instituto de Estudios Estratégicos y Políticas Públicas. (2015). Matriz de indicadores, diagnóstico y seguimiento a la Trata de Personas en Centroámerica. Instituto de Estudios Estratégicos y Políticas Públicas. Managua: Instituto de Estudios Estratégicos y Políticas Públicas. Obtenido de: https://www.ieepp.org/publicaciones/ crimen-organizado-y-delitos-conexos/publicacion-3-478/

Kelley, J. \& Simmons, B. (2015). Politics by Number: Indicators as Social Pressure in International Relations. American Journal of Political Science, 59(1), 55-70. doi:10.1111/ajps.12119

Marry, S. E. (2016). Measuring the Unmeasurable: The US Trafficking in Persons Reports. En S. E. Merry, The Seductions of Quantification: Measuring Human Rights, Gender Violence, and Sex Trafficking. Chicago: Chicago Series in Law and Society. Obtenido de: https://www.press. uchicago.edu/ucp/books/book/chicago/S/ bo23044232.html

Mesa Intersectorial sobre Trata de Personas. (2015). Plan de Acción Nacional contra la trata de personas 2015 - 2018. Gobierno de Chile. Obtenido de: https://biblioteca.digital.gob.cl/handle/123456789/737

Ministerio del Interior. (2012). Manual para la formulación de políticas públicas de lucha contra la trata de personas y el diseño y ejecución de planes de acción departamentales, distritales y/o municipales. Obtenido de Librería en línea de la OIM: https://publications.iom.int/es/books/manual-para-la-formulacion-de-politicas-publicas-de-lucha-contra-la-trata-de-personas-y-el

Ministerio del Interior, UNODC, \& OIM. (2014). VII encuentro nacional de comités departamentales de lucha contra la trata de personas. Bucaramanga, Octubre 23 y 24 de 2014.

Neumayer, E., Dreher, A. \& Seo-Young, C. (2011). The spread of anti-trafficking Policies: Evidence from a new index. CESifo Working Paper(3376), 1-47. Obtenido de: https://poseidon01.ssrn. com/delivery.php? ID=6160640021060720701 1603012003111312103701602509304400701 4073020026003100074069116120028062030 1240450330100250770870901101211220460 8307806108310206701706409112300100003 0016120064065077114106112064113103092 1241070

OEA. (2007). Lineamientos para la elaboración de indicadores de progreso en materia de derechos económicos, sociales y culturales. Washington: Organización de Estados Americanos.

OIM. (2005). Data and research on human trafficking: A global Survey. Geneva: International Organization for Migration.

OIM. (2012). Manual para la formulación de Políticas Públicas de Lucha Contra la Trata de Personas y el diseño y ejecución de Planes de Acción Departamentales, Distritales y/o Municipales. Bogotá: Organización Internacional para las Migraciones. Obtenido de: https://publications.iom.int/es/books/manual-para-la-formulacion-de-politicas-publicas-de-lucha-contra-la-trata-de-personas-y-el

OIM. (2016). Indicadores de cumplimiento compromisos adquiridos en materia del abordaje integral de la Trata de Personas. Organización Internacional para las Migraciones. San José: Organización Internacional para las Migraciones. Obtenido de: https://rosanjose.iom.int/site/ sites/default/files/Indicadores\%20de\%20cumplimiento\%20-\%20Compromisos\%20adquiridos\%20en\%20materia\%20de\%20abordaje\%20 integral\%20de\%20la\%20trata\%20de\%20personas\%20\%20.pdf

Procuraduría General de la Nación et al. (2018). Modelo de Vigilancia Preventiva a las acciones del Estado Colombiano en materia de Lucha contra la Trata de Personas. Colombia: Procuraduría General de la Nación. Obtenido de: https://www.procuraduria.gov.co/portal/?option=net.comtor. cms.frontend.component.pagefactory.SPForoComponentPageFactory\&action=view\&key=53

Reyes, J., Vargas, J., \& Aceros, J. (2018). Análisis de las medidas de asistencia a víctimas de trata de 
personas en Colombia en perspectiva de derechos humanos. Opinión Jurídica, 17(33) (pp.99-122). doi:10.22395/ojum.v17n33a4

Rudolph, A. \& Schneider, F. (2017). International human trafficking: Measuring clandestinity by the structural equation approach. Social Inclusion, 5(2), (pp.39-58). doi:10.17645/si.v5i2.909

Sarfaty, G. A. (2015). Measuring Corporate Accountability through Global Indicators. En S. Merry, K. Davis, \& B. Kingsbury, The Quiet Power of Indicators: Measuring Governance, Corruption, and Rule of Law (pp. 103-132). Cambridge: Cambridge University Press. doi:10.1017/ CBO9781139871532.004

Seo-Young, C. (2015). Measuring Anti Trafficking PolicyIntegrating Text and Statistical Analyses. Social Science Quarterly, 96(2), 656-683. doi:10.1111/ ssqu. 12153

Steffnizzi, S. (2007). Measuring the Non-Measurable: Towards the Development of Indicators for Measuring Human Trafficking. En E. Savona, \& S. Steffnizzi, Measuring Human Trafficking (pp.45-53). New York: Springer. doi:10.1007/0387-68044-6_6

UN.GIFT. (2010). Indicadores de trata de personas. UNODC. Obtenido de: https://www.unodc.org/ documents/human-trafficking/HT_indicators_S_LOWRES.pdf

UNODC. (2000). Protocolo para prevenir, reprimir y sancionar la trata de personas, especialmente en mujeres y niños que complementa la Convención de las Naciones Unidas contra la Delincuencia Organizada Trasnacional. Obtenido de Oficina del Alto Comisionado para los Derechos Humanos: https://www.ohchr.org/Documents/ ProfessionalInterest/ProtocolTraffickingInPersons_sp.pdf

UNODC. (2018). Global report on trafficking in Persons. Vienna: UNODC. Obtenido de: https://www. unodc.org/e4j/data/_university_uni_/global_ report_on_trafficking_in_persons_2018.html

Van Dyke, R. (2017). Monitoring and Evaluation of Human Trafficking Partnerships in England and Wales. Anti-Trafficking Review (8). doi:10.14197/ atr.20121788

Vargas-Parra, J., Aceros, J., Reyes, J. \& Urón, R. (2018). Cartilla didáctica Sentipensar la asistencia inmediata a las víctimas de trata de personas. Bucaramanga: Universidad Autónoma de Bucaramanga. Obtenido de http://www.unab.edu. co/pagina/sentipensar

Walk Free Foundation. (2018). The Global Slavery Index. Nedlands: Walk Free Foundation. Obtenido de https: / /www.globalslaveryindex.org/resources/downloads/
Young, S., Dreherb, A., \& Neumayerc, E. (2012). The Determinants of Anti-trafficking Policies - Evidence from a New Index. APSA 2011 Annual Meeting Paper, (págs. 1-37). Seattle. Obtenido de https://papers.ssrn.com/sol3/papers.cfm?abstract_id=1900194

\section{Anexo 1. Indicadores}

A continuación, se encuentra la lista de indicadores clasificados por dimensiones o categorias en relación con los principios y directrices recomendados sobre derechos humanos y trata de personas (ACNUDH, 2010) y con los ejes de la estrategia nacional de lucha contra la trata de personas en Colombia 2012-2018.

En la columna denominada 'Fuente', la enumeración corresponde a:

1. Dirección de información y análisis Ministerio de Justicia y Seguridad Pública del Salvador (2016). Fichas de indicadores para el sistema nacional de información sobre el delito de trata de personas en El Salvador

2. Gobierno de Chile (2015). Plan de Acción Nacional contra la Trata de Personas 20152018

3. Procuraduría general de la Nación (2018). Modelo de Vigilancia Preventiva a las acciones del Estado Colombiano en materia de Lucha contra la trata de personas

4. Ministerio del Interior (2012). Manual para la formulación de Políticas Públicas de Lucha Contra la Trata de Personas y el diseño y ejecución de Planes de Acción Departamentales, Distritales y/o Municipales

5. Bocanument, M. (2012). Política Pública Sobre trata de personas en MedellínColombia. Prevención, Asistencia y Protección a Víctimas y Posibles Víctimas de la trata de personas. Estudio de Caso

6. Instituto de Estudios Estratégicos y Políticas Públicas (2015). Matriz de indicadores diagnóstico y seguimiento de la trata de personas en Centroamérica.

7. OIM (2016). Indicadores de Cumplimiento. Compromisos adquiridos en el abordaje integral de la trata de personas 


\section{Dimensión o categoria}

1) Marcos normativos

Indicadores

Fuente

Implementada a nivel nacional la Convención contra la Delincuencia Organizada 6

Transnacional.

Implementado a nivel nacional el Protocolo de las Naciones Unidas para Prevenir, 6

Reprimir y Sancionar la trata de personas, especialmente Mujeres y Niños.

Implementado a nivel nacional el Pacto Internacional de Derechos Civiles y

6

Políticos, concerniente al artículo 8, sobre la prohibición de la esclavitud.

Ratificado el Protocolo Facultativo por el que se reconoce la competencia del

Comité de Derechos Humanos para recibir y considerar comunicaciones al respecto.

Implementada a nivel nacional la Convención sobre los Derechos del Niño en lo que atañe al artículo 35 , sobre la prohibición de la trata de niños para cualquier fin o en cualquier forma.

Ratificado el Protocolo Facultativo concerniente a la venta de niños, la prostitución infantil y la utilización de niños en la pornografía.

Ratificado el Protocolo Facultativo por el que se reconoce la competencia del

Comité de los Derechos del Niño para recibir y considerar comunicaciones al respecto.

Implementada a nivel nacional la Convención sobre la Eliminación de Todas las

Formas de Discriminación contra la Mujer en lo que atañe al artículo 6, sobre la supresión de todas las formas de trata de mujeres.

Ratificado el Protocolo Facultativo por el que se reconoce la competencia del

Comité para la Eliminación de la Discriminación contra la Mujer para recibir y considerar comunicaciones al respecto.

Implementada a nivel nacional la Convención Americana sobre Derechos

Humanos en lo concerniente al artículo 6, que prohíbe la esclavitud y la servidumbre.

La legislación nacional ha sido armonizada conforme al artículo 2B de la

Convención de Belém do Pará, que considera la trata de personas como una manifestación de violencia contra la mujer.

Implementado a nivel nacional el Convenio Centroamericano para proteger en el 6 proceso penal a las víctimas y testigos de trata de personas.

Incluida la prevención y sanción de todas las formas de trata de personas,

nacional o transnacional, y sea que esté o no vinculada a la delincuencia organizada.

La Ley contra la trata de personas se aplica dentro y fuera del territorio.

El consentimiento otorgado por la víctima es irrelevante en el proceso.

6

6

Disposiciones jurídicas establecen la adopción de medidas integrales de apoyo y 6 protección a las víctimas.

Disposiciones penales y procesales ajustadas para mejorar la investigación y

6 sanción del delito.

Vinculada jurídicamente la trata de personas con el crimen.

6

Lineamientos en materia laboral, migratoria y de atención a víctimas, entre otras, 6 afectados por la Ley contra la trata de personas.

Elaborado, aprobado y en vigor el reglamento de la Ley contra la trata de 6 personas.

Elaborado, aprobado y en vigor el reglamento nacional de coordinación

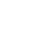

(2)

(1)

$+2$

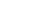

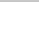

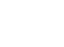

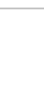


Aprobado el Plan Estratégico Nacional contra la trata de personas.

Las resoluciones internas de las instituciones vinculadas con la trata de personas 6 están alineadas con la ley nacional en materia de trata de personas.

Elaborada y aprobada la política pública o el plan nacional contra la trata de 6 personas.

La trata de personas se encuentra tipificada con los fines mínimos que menciona 7 el Protocolo de Palermo.

Existe una categoría migratoria temporal o permanente para personas víctimas de 7 trata de personas.

Existe normativa que regula la denegación de la entrada al país o la revocación de 7 visa a personas implicadas en el delito de trata de personas o conexos.

Existe una política nacional contra la trata de personas, incluyendo un capítulo 7 sobre la prevención de la trata de personas, así como iniciativas sociales y económicas.

La tentativa de comisión de la trata de personas se encuentra tipificada como $\quad 7$ delito.

La complicidad en la comisión de la trata de personas se encuentra tipificada $\quad 7$ como delito.

La organización y dirección de otras personas para la comisión de la trata de $\quad 7$ personas se contempla como un delito.

La utilización de medios de transporte explotados por transportistas comerciales $\quad 7$ para la comisión de la trata de personas se encuentra tipificada como delito.

La obligación de transportistas de asegurarse de que cada pasajero cuente con la 7 respectiva documentación de viaje e identidad está regulada y existe una sanción en caso contrario.

2) Detección, Número de posibles víctimas de trata de personas detectadas.

Número de víctimas de trata de personas confirmadas.

Número de casos de trata de personas confirmados.

Número de nacionales colombianos que se encuentran en el exterior, cuyo

lugar de origen corresponde al departamento del comité que está aplicando los instrumentos.

Índice de presión del desplazamiento forzado interno del departamento.

4

Número de viajeros nacionales e internacionales que llegaron al departamento.

4

Número de casos de reclutamiento de menores de edad por grupos armados

ilegales.

Número de adolescentes y jóvenes embarazadas o que ya son madres en el

departamento.

Número de trabajadoras sexuales y de menores en explotación sexual en el departamento.

Número de personas que ejercen mendicidad en lugar público o abierto al público 4 en el departamento.

Número de empleados y empleadas de servicio doméstico en el departamento. $\quad 4$

Responder Sí o NO, el departamento cuenta con información sobre el perfil de las 4 víctimas.

Responder Sí o NO, el departamento cuenta con información sobre las rutas. 
Responder SÍ o NO, el departamento cuenta con información sobre las modalidades de trata de personas.

Los actores susceptibles de detectar casos de trata de personas reciben

capacitación sobre indicadores de identificación, en especial los que conciernen a la niñez y a otros grupos en situación de riesgo.

Cantidad de las víctimas acreditadas por la autoridad competente desde la entrada en vigor de la ley.

Elaborado un manual de procedimientos para la identificación y remisión de las 6 víctimas.

Existen protocolos para la detección y atención primaria de víctimas de trata de 7 personas en las zonas de tránsito migratorio.

Existen controles de calidad y uso legítimo de los documentos de viaje o identidad, 7 que impiden la falsificación o alteración de los mismos, así como que sean expedidos a nombre de un estado para ser utilizados ilícitamente.

Tipo de victimario de estos casos/el total de hechos conocidos. 5

Rutas y redes de comercio de la explotación de la prostitución de menores/el total 5 de las identificadas.

Número de estas rutas intervenidas sobre el total de las identificadas.

Lugar de origen y de destino de estas víctimas.

5

Número de víctimas mayores de explotación de la prostitución afrodescendientes / 5 el total de víctimas mayores de explotación de la prostitución identificadas.

Número de víctimas mayores de explotación de la prostitución indígenas/el total 5 de víctimas mayores de explotación de la prostitución identificado.

Número de víctimas mayores de explotación de la prostitución que hacen parte de 5 la población en situación de desplazamiento forzado/el total de víctimas mayores de la explotación de la prostitución.

Número de denuncias recibidas por prostitución donde la víctima es un mayor/el 5 total de denuncias recibidas por prostitución.

Número de investigaciones iniciadas al año por explotación de la prostitución de 5 mayores/el total de hechos conocidos.

Tipo de victimario/El total de hechos conocidos.

Rutas y redes de comercio de la explotación de la prostitución de mayores sobre el 5 total de las identificadas.

Número de estas rutas intervenidas sobre el total de las identificadas.

5

Número de víctimas de la explotación para pornografía/el total de víctimas de 5 trata de personas identificado.

Edades de estas víctimas..

Sexo de estas víctimas.

Lugar de origen y de destino de estas víctimas.

Número de estas víctimas afrodescendientes/el total de víctimas de pornografía. 5

Número de estas víctimas indígenas/el total de estas víctimas de pornografia. 5

Número de estas víctimas que hacen parte de la población en situación de 5 desplazamiento forzado/el total de víctimas de pornografía.

Número de estas víctimas menores atendidas por el ICBF/el total de víctimas 5 menores de pornografía.

Número de denuncias recibidas por explotación pornográfica/el total de denuncias recibidos por trata de personas. 
Número de investigaciones iniciadas al año por la explotación de pornografía de 5 otra persona/el total de hechos conocidos.

Tipo de victimario/el total de hechos conocidos.

Rutas y redes de comercio identificadas para la explotación de pornografía de $\quad 5$ mayores y/o menores de edad.

Número de estas rutas y redes intervenidas/el total de las identificadas. $\quad 5$

Número de víctimas menores atendidas por el ICBF/el total de víctima menores de 5 matrimonio servil.

Número identificado de menores de edad en el mercado laboral.

Edad de estos menores.

5

Sexo de estos menores.

5

Actividad económica en el que se explotan.

5

Tipo de oficio que desempeñan.

5

Cuántos de ellos cuentan con permiso del Ministerio de la Protección Social.

5

Número de estos menores afrodescendientes sobre el total de menores víctimas de 5 trabajo forzado.

Número de estos menores indígenas/el total de menores víctimas de trabajo

5

forzado.

Número de estos menores de la población en condición de desplazamiento forzoso 5 sobre el total de menores víctimas de trabajo forzado.

Número de menores usuarios del programa de atención a la niñez en condición 5 de explotación laboral del ICBF sobre el número de víctimas menores de trabajo forzoso

Escolaridad.

Número de medios de comunicación donde se difunde la campaña nacional de

3) Prevención de la trata de personas sensibilización.

Número de instituciones que difundieron el material de la campaña nacional de sensibilización.

Número de descargas o reproducciones del material campaña nacional de sensibilización

Número anual de visitas a la página web de la Mesa Intersectorial sobre Trata de 2

Personas

Número de enlaces apuntados a la página web de la Mesa Intersectorial sobre

Trata de Personas

Número de instituciones de la MITP que difundieron material el Día de Acción contra la trata de personas el 2016.

Número de instituciones de la MITP que difundieron material el día de acción contra la trata de personas el 2017.

Número de instituciones que recibieron y utilizaron el material de difusión.

2

Número de instituciones en las que se implementó la estrategia de sensibilización. 2

Total de acciones realizadas en educación de derechos a grupos vulnerables.

Número de servicios telefónicos que han incorporado la temática de trata de 2 personas.

Número de medios de comunicación que tienen conocimiento sobre la temática de 2 trata de personas. 
Número de herramientas para el fortalecimiento técnico, en programas de

prevención y formación, dirigidos a las Organizaciones de la Sociedad Civil

implementadas/Número de herramientas para el fortalecimiento técnico en

programas de prevención y formación dirigidos a las Organizaciones de la

Sociedad Civil diseñadas.

Número de estrategias implementadas para la generación de procesos de

responsabilidad empresarial encaminados a la prevención de la trata de personas

diseñadas.

Número de estrategias de información, educación y comunicación

3

implementadas/Número de estrategias de información, educación y comunicación

diseñadas.

Número de acciones implementadas en el marco de procesos de cooperación

3

técnica en materia de prevención del delito de trata de personas entre entidades

territoriales.

Número de estrategias implementadas para la difusión de la oferta sectorial

identificada de promoción de derechos humanos y de generación de

oportunidades para la población en general.

Número de acciones implementadas para el fortalecimiento y la promoción de

iniciativas sociales económicas y culturales orientadas a prevenir la trata de personas.

Número de campañas de prevención en materia de trata de personas.

Número de personas que participaron en las jornadas de sensibilización en

4 materia de trata de personas.

Número de publicaciones elaboradas, impresas y distribuidas (publicadas) en 4 materia de trata de personas en el departamento.

Número de investigaciones en materia de prevención de la trata de personas $\quad 4$ adelantadas en el departamento.

Número de servidores públicos que recibieron capacitación en materia de prevención por parte del departamento.

Tipo de capacitación de quienes atienden la línea telefónica.

5

Número de llamadas recibidas al mes sobre la capacidad de atención.

5

Existencia de línea telefónica departamental/una línea funcionando.

5

Medios de difusión de la existencia de la línea telefónica/los medios disponibles 5 para difusión.

Desarrolladas campañas de sensibilización sobre los efectos y consecuencias del 6 delito y sobre el papel de la sociedad.

Creado un sitio web oficial con información sobre el tema.

6

Los medios de comunicación brindan apoyo sin fines de lucro difundiendo

mensajes de sensibilización sobre la trata de personas.

Creado e implementado un currículo universitario nacional con contenidos sobre 6 la trata de personas.

Existen programas para atender los factores de vulnerabilización a la trata

de personas. En estos programas se intervienen factores como la pobreza y el desempleo mediante acciones educativas, sociales y culturales, que también desestimulan la demanda de Víctimas de trata.

Se han realizado campañas de información y difusión contra la trata de personas. 7

Número de programas y actividades formulados para monitorear la trata de

personas/el total de programas y actividades formuladas.

Número de programas para monitorear la trata de personas ejecutados. 
Número de programas y actividades formulados para prevenir la trata de personas/el total de programas y actividades formulado.

Número de programas ejecutados para prevenir la trata de personas.

Número de programas y actividades formulados para erradicar la trata de personas/el total de programas y actividades formulados.

Número de programas formulados para erradicar la trata de personas ejecutados. 5

4) Protección y asistencia
Número de víctimas del delito de trata de personas que ha recibido atención médica y clínica.

Número de víctimas del delito que han recibido los insumos para atender sus necesidades básicas de higiene personal, alimentación y vestuario.
5

Número de víctimas de trata que han recibido asesoramiento legal.

1

Número de víctimas de trata de personas que han recibido atención psicológica y 1 psiquiátrica.

Número de víctimas de trata de personas que han recibido asistencia de

1

traducción e interpretación de acuerdo con su idioma y condición de discapacidad

(DGME y MRREE).

Número de medidas de protección dictadas en las juntas de protección ante

1 posibles casos de trata de personas (CONNA).

Número de víctimas nacionales del delito de trata de personas que han recibido alojamiento albergues (ISNA, ISDEMU y UTE por medio de la FGR).

Número de personas que han ingresado al Programa de protección a víctimas y 1 testigos (UTE).

Número de víctimas de trata de personas que han sido incorporadas a la bolsa de 1 trabajo o programas de orientación vocacional (MINTRAB).

Número de víctimas extranjeras del delito de trata que han recibido un

1 alojamiento en CAIM-DGME.

Número de víctimas de trata de personas retornadas (MRREE).

1

Número de víctimas de trata de personas que han sido incorporadas al sistema

1 educativo (MINED).

Número de posibles víctimas de trata de personas asistidas por consulados salvadoreños en el extranjero.

Número de cumplimientos de prestaciones comprometidas a partir del análisis de 2 casos/Total de prestaciones comprometidas por las instituciones tras el análisis de caso.

Informe validado en torno al cumplimiento del Estado de Chile en materia de asistencia a víctimas de trata de personas, en los términos de la Convención de las Naciones Unidas contra la Delincuencia Organizada Transnacional .

Número de informes técnicos elaborados/Número total de brechas detectadas en el informe en torno al cumplimiento del Estado de Chile en materia de asistencia a víctimas de trata de personas, en los términos de la Convención de las Naciones Unidas contra la Delincuencia Organizada Transnacional.

Número de informes técnicos entregados y discutidos con las instituciones identificadas como responsables de dar respuesta a las brechas detectadas.

Número de mecanismos para brindar la asistencia inmediata y/o mediata de manera oportuna, diferencial, integral y eficiente, en el marco de la protección de la dignidad humana y de los derechos de las víctimas diseñados. Número de casos que recibieron asistencia mediata. 
Número de programas medidas y herramientas para garantizar las asistencia

inmediata.

Número de casos que recibieron asistencia inmediata/Número de casos

identificados.

Número de mecanismos de articulación y coordinación de la oferta institucional

3 para que las víctimas puedan obtener el restablecimiento de sus derechos en el marco de la asistencia mediata.

Un informe trimestral en donde se relacionen como mínimo las siguiente variables: servicios brindados en el marco de la asistencia inmediata y mediata, trata interna o externa, modalidad, sexo, lugar de origen y destino, nivel educativo.

Número de protocolos y rutas de protección asistencia que garanticen el

fortalecimiento y articulación de programas y medidas de protección y asistencia entre las diferentes instituciones y actores que intervienen en el proceso, a nivel nacional, departamental, distrital y municipal en implementación.

Número de servidores públicos de las instituciones competentes en la protección y 3 asistencia a las víctimas capacitados en el tema clasificados por región y entidad.

Número de víctimas de trata de personas interna asistidas por el departamento.

Número de víctimas de trata de personas externa asistidas por el departamento.

Número de casos en que haya recibido al menos uno de los servicios

4

contemplados en la etapa de asistencia de reintegración.

Número de actividades completadas de acuerdo con el número de actividades $\quad 4$

aprobadas en el PAD en el eje de asistencia y atención.

Número de víctimas que recibieron alguno de los servicios de asistencias de 4

emergencia.

Número de casos asistidos de trata de personas interna que tuvieron seguimiento 4 por parte de las instituciones del comité.

Número total de casos asistidos de trata de personas externa que tuvieron $\quad 4$ seguimiento por parte de las instituciones del comité.

Número de menores de edad asistidos por trata de personas en el departamento. $\quad 4$

Número de víctimas de trata de personas que fueron beneficiarias de iniciativas de 4 generación de ingresos realizadas por el departamento.

Número de víctimas de trata de personas externa conocidas por los miembros del 4 comité.

Número de víctimas de trata de personas interna conocidas por los miembros del 4 comité.

Tipo y número de programas formulados para la protección de las víctimas/el 5 total de los programas formulados relacionados con la problemática.

Tipo y número de estos programas para la protección de las víctimas ejecutados / 5 el total de estos formulado.

Nivel de ejecución de cada uno de estos programas para la protección de las 5 víctimas .

Tipo y número de programas formulados para la orientación técnica de las

\section{5} víctimas / el total de los programas formulados relacionados con la problemática.

Tipo y número de programas para la orientación técnica de las víctimas 5 ejecutados / el total de estos formulados.

Nivel de ejecución de cada programa de orientación técnica de las víctimas.

Tipo y número de programas formulados para la atención integral gratuita sobre 5 el total de los programas formulados relacionados con la problemática. 
Tipo y número de programas para la atención integral gratuita ejecutados / e total de estos formulados.

Nivel de ejecución de cada programa de atención integral gratuita.

5

Tipo y número de programas formulados para la capacitación de las víctimas / el 5 total de los programas formulados relacionados con la problemática.

Tipo y número de estos programas ejecutados / el total de estos formulados. 5

Nivel de ejecución de cada uno de ellos.

5

Número de víctimas beneficiarias de la atención médica gratuita / el total de

5 víctimas identificado.

Número de víctimas beneficiarias de la atención psicológica gratuita / el total de 5 víctimas identificado.

Número de víctimas beneficiadas de la atención social gratuita / el total de 5 víctimas identificado.

Número de víctimas beneficiadas de la atención jurídica gratuita / el total de

5 víctimas identificado.

Número de víctimas beneficiadas de la capacitación / el total de víctimas

5 identificado.

Número y tipo de programas formulados para prevenir la revictimización / el total 5 de programas formulados relacionados con la problemática.

Número y tipo de estos programas ejecutados o en ejecución para prevenir la 5 revictimización / el total de los formulados.

Nivel de ejecución de cada uno de ellos.

Número de personas usuarias de estos programas / el total identificado de 5 víctimas.

Número de personas revictimizadas sobre el total identificado de víctimas. 5

Incluida la protección y asistencia a las víctimas en cuanto a protección de 6

identidad, seguridad física, indemnización, asistencia social, y otros servicios sociales.

Las víctimas de la trata de personas en ningún caso son detenidas, acusadas ni $\quad 6$ procesadas por haber entrado o por residir ilegalmente en los países de tránsito y destino, ni por haber participado en actividades ilícitas, en la medida en que esa participación sea consecuencia directa de su situación de víctimas.

Medidas institucionalizadas para evitar la revictimización

Medidas de protección de la intimidad y la identidad de víctimas y testigos

durante las actuaciones penales.

Se brinda acompañamiento o representación legal para las víctimas durante los

6 procesos judiciales.

Elaborado un protocolo de asistencia y atención para víctimas nacionales de trata 6 de personas en el extranjero.

Habilitadas y fortalecidas las instalaciones para el alojamiento adecuado, accesible y seguro de las víctimas, bajo la administración de autoridad competente.

Las víctimas tienen garantizado el acceso a medidas administrativas o judiciales 6 para su protección.

Adoptadas las medidas destinadas a prever la recuperación física, psicológica y 6 social de las víctimas.

Procesados y registrados todos los datos pertinentes de las víctimas y de los testigos. 
Garantizada la confidencialidad de toda la información intercambiada entre una

víctima y un profesional que presta servicios de asistencia (jurídica, psicológica,

médica).

Establecidas multas y sanciones para casos de vulneración de la confidencialidad 6

de una víctima.

Adoptadas las medidas para proteger debidamente a las víctimas y testigos que $\quad 6$ participan en procesos penales.

Establecidos lineamientos para que las víctimas puedan manifestar su opinión, $\quad 6$ necesidades, intereses y preocupaciones, y que se les tome en cuenta en los procedimientos judiciales o administrativos relacionados con el delito.

Brindados los servicios de alojamiento durante el tiempo necesario. 6

Proporcionados alimentos, vestimenta y productos de higiene personal. 6

Prestados servicios de asistencia a las víctimas y a sus familiares.

A las víctimas se les informa de sus derechos, incluido, de ser necesario, el

derecho a contar con servicios de traducción e interpretación.

A las víctimas que son menores de edad, personas en condición de discapacidad o 6 adultas mayores se les aplican medidas de atención especial.

Establecidas medidas para mejorar el estado físico y mental de la víctima, incluso 6 tratamientos que propicien la restitución de sus derechos.

De ser necesario, se les concede a las víctimas un estatus migratorio temporal,

6 prolongado o permanente, tras un análisis técnico detallado y con la anuencia de la propia víctima.

Existe capacidad para gestionar la repatriación o el reasentamiento de la víctima, 6 cuando proceda, y con la anuencia de la propia víctima.

Fomentadas oportunidades de empleo, educación y capacitación para las víctimas 6 y sus dependientes.

Adoptadas medidas para que las víctimas puedan permanecer en el país donde 6 fueron rescatadas.

Concedido un período de recuperación y reflexión, independientemente de que 6 exista o no un acuerdo previo para prestar testimonio como testigo.

A las víctimas y a sus dependientes se les otorga un permiso de residencia con 6 posibilidad de renovación.

En todo procedimiento de repatriación de una víctima se acata el principio de no 6 devolución y se prohíbe el trato inhumano o degradante.

Se emiten documentos de viaje y otras autorizaciones necesarias para la repatriación.

Gestionada la coordinación y el apoyo logístico para la repatriación de la víctima y 6 de las personas a su cargo.

Realizado el proceso de reasentamiento con las debidas garantías.

Las autoridades nacionales competentes garantizan un procedimiento de resolución expedito y técnicamente fundamentado, conforme al derecho humanitario.

Existe un mecanismo nacional para la protección y asistencia a Víctimas de trata 7 de personas.

Existen programas y servicios dirigidos a hombres y mujeres menores de edad 7 víctimas de trata de personas.

Existen programas y servicios dirigidos a hombres adultos víctimas de trata de $\quad 7$ personas. 
Existen programas y servicios dirigidos a mujeres adultas víctimas de trata de personas.

La privacidad e identidad de las víctimas ha sido protegida en el $100 \%$ de los casos.

El 100\% de los casos de víctimas han recibido servicios de seguridad física.

7

Existe un registro de víctimas de trata nacionales y extranjeras que efectivamente 7 fueron asistidas y protegidas.

Existe el servicio de alojamiento para mujeres víctimas de trata en el $100 \%$ de los 7 casos requeridos.

Existe el servicio de alojamiento para hombres víctimas de trata en el 100\% de los 7 casos requeridos.

Existe el servicio de alojamiento para personas menores de edad Víctimas de trata 7 en el 100\% de los casos requeridos.

Existe el servicio de atención médica en el 100\% de los casos requeridos. $\quad 7$

Existe el servicio de atención psicológica en el 100\% de los casos requeridos. $\quad 7$

Existe un fondo de asistencia material a personas víctimas de trata.

$\begin{array}{ll}\text { Existe algún programa de reintegración que contemple alternativas para proveer } & 7\end{array}$ de empleo a personas sobrevivientes a la trata de personas.

$\begin{array}{ll}\text { Existe algún programa de reintegración que contemple alternativas de educación } & 7\end{array}$ formal y técnica para personas sobrevivientes a la trata de personas.

Existen protocolos de repatriación con enfoque de riesgo. 7

Todas las personas sobrevivientes de la trata participan en procesos de reintegración y protegidas de la revictimización (recaptación).

\begin{tabular}{|c|c|c|}
\hline $\begin{array}{l}\text { 5) Penalización, } \\
\text { sanción y } \\
\text { reparación }\end{array}$ & Número de casos de trata de personas denunciados. & 1 \\
\hline & Número de casos de trata de personas investigados. & 1 \\
\hline & Número de casos de trata de personas investigados en estado activo. & 1 \\
\hline & Número de casos de trata de personas con acusación. & 1 \\
\hline & Número de casos de trata de personas en etapa de sentencia. & 1 \\
\hline & Número de casos de trata de personas con sentencia absolutoria. & 1 \\
\hline & Número de casos de trata de personas con sentencia condenatoria. & 1 \\
\hline & $\begin{array}{l}\text { Número de funcionarios capacitados / } \mathrm{N}^{\circ} \text { total de funcionarios de BICRIM, } \\
\text { BRISEXME, POLIN, SIP de Carabineros, Capitanías de Puerto, Oficina } \\
\text { Comunitaria, CENCO, esas unidades. }\end{array}$ & 2 \\
\hline & $\begin{array}{l}\text { Número de unidades cuyos funcionarios de BICRIM, BRISEXME, POLIN, SIP } \\
\text { de Carabineros, Capitanías de Puerto, Oficina Comunitaria, CENCO, que han } \\
\text { recibido capacitación/ } N^{\circ} \text { total de unidades. }\end{array}$ & 2 \\
\hline & Número total de aspirantes de formación policial que hayan asistido a las charlas. & 2 \\
\hline & Número total de fiscalizadores capacitados por cada dirección del trabajo. & 2 \\
\hline & $\begin{array}{l}\text { Acápite incluido sobre trata de personas en instructivo para los fiscalizadores } \\
\text { sanitarios. }\end{array}$ & 2 \\
\hline & Número total de fiscalizadores sanitarios capacitados. & 2 \\
\hline & Número de operadores del Programa Denuncia Seguro capacitados. & 2 \\
\hline & $\begin{array}{l}\text { Número de Protocolos de actuación de cada integrante de la subcomisión de } \\
\text { control aprobados por cada institución. }\end{array}$ & 2 \\
\hline
\end{tabular}


Guía elaborada y distribuida a miembros MITP y puntos focales regionales.

2

Informe denuncias de trata de personas, y sus resultados, interpuestas por el

2

Programa Denuncia Seguro entre el 2015 y el 2018.

Número total de funcionarios capacitados en unidades policiales especializadas.

Número de Fiscales capacitados.

Número jueces de garantía y miembros de tribunales orales en lo penal asistentes 2

a la instancia de capacitación.

Diagnóstico validado de causas formalizadas al 31 de diciembre 2014 y listado de 2

dificultades para la interposición de medidas cautelares reales y demandas civiles

por parte de los querellantes que lo han efectuado.

Número de causas en las que se interpuso medidas cautelares reales a favor

2

de las víctimas de trata de personas /Número de causas en las que era posible

interponer medidas cautelares reales a favor de las víctimas de trata de personas.

Número de demandas civiles interpuestas a favor de las víctimas de trata de 2

personas/ Número de posibles demandas civiles a favor de las víctimas de trata de personas.

Propuesta de actualización validada de la Guía de Buenas Prácticas en la 2

Investigación Criminal del Delito de trata de personas.

Número de acciones implementadas para el fortalecimiento de la capacidad

operativa de las entidades competentes en la investigación y judicialización del

delito de trata de personas.

Número de acciones implementadas para la actualización de estrategias de investigación de la trata de personas.

Número de víctimas participando en procesos de justicia restaurativa trimestralmente.

Número de decisiones judiciales a través de las cuales se declaró la extinción de 3

dominio derivada del delito de la trata de personas.

Número de sentencias condenatorias Interna y Externa por el delito de trata de 3

personas.

Informe de actividades investigativas para la judicialización y sanción de delitos

conexos a la trata de personas.

Número de operadores de justicia y funcionarios de entidades que apoyan su 3

administración capacitados en el tema, clasificados por región y entidad.

Número de casos de trata de personas conocidos por las autoridades en el

4

departamento por cada una de las modalidades (explotación sexual, explotación

laboral o trabajos forzados, mendicidad ajena, reclutamiento forzado, matrimonio

servil, extracción ilegal de órganos).

Número de actividades completadas de acuerdo con el número de actividades $\quad 4$

aprobadas en el PAD en el eje de judicialización e investigación.

Número de personas que están cumpliendo una condena por el delito de trata de 4 personas.

Tipo y número de programas formulados para detectar, perseguir y desarticular 5

redes de trata / el total de programas formulados relacionados con la

problemática.

Tipo y número de estos programas ejecutados / los formulados.

Recursos destinados para aumentar la capacidad de detección, persecución y 5

desarticulación de las redes de trata de personas / el total de los recursos para la

problemática; porcentaje de estos recursos ejecutados.

El consentimiento otorgado por la víctima es irrelevante en el proceso. 
Posibilidad de sancionar a personas jurídicas como sujetos activos del delito.

6

Agilizados los procesos de investigación y sanción del delito.

6

Se obtienen recursos de la venta o de la administración de los bienes,

6

instrumentos, dineros o valores aprehendidos o decomisados a las personas

naturales o jurídicas procesadas por el delito de trata de personas y actividades

conexas.

Las instalaciones policiales son adecuadas para garantizar la seguridad y la

atención de las víctimas y de los victimarios.

Son adecuadas las salas de debates y las oficinas judiciales donde se realizan

6

audiencias de "alto riesgo" vinculadas con casos de delincuencia organizada

transnacional.

Se satisfacen las necesidades técnicas (equipamiento, tecnología de punta,

cámaras de Gesell) para modernizar la obtención de pruebas del delito.

Los programas y planes de protección y movilización cubren los correspondientes $\quad 6$ gastos del personal encargado de investigar y procurar justicia.

Iniciadas acciones civiles para reclamar resarcimiento por los daños materiales e $\quad 6$ inmateriales ocasionados por el delito.

Facilitada a la víctima la posibilidad de iniciar un juicio civil por daños y

perjuicios o de presentar su caso ante otro tribunal competente.

El Estado resarce a las víctimas en caso de que los funcionarios públicos u otros 6 agentes que actúen a título oficial o cuasi oficial hayan violado la legislación penal nacional en su trato a las víctimas o hayan faltado a la debida indemnización; asimismo, cuando la indemnización procedente del victimario no fuese suficiente. Existen garantías procesales para las Víctimas de trata, en especial que reciban $\quad 7$ información y se tome en cuenta su opinión y preocupaciones.

Existen sentencias contra tratantes.

7

Las personas sobrevivientes a la trata han sido indemnizadas o recibido un monto 7 económico por los daños sufridos.

6) Coordinación, Número de acuerdos y memorandos de entendimiento suscritos entre Colombia y 2 cooperación, sostenibilidad y acceso a recursos otros países.

Un informe sobre los avances en la implementación de los planes de acción

derivados de los acuerdos y memorandos suscritos.

Número de charlas efectuadas por organizaciones o instituciones que no participen de la MITP.

Número de acuerdos de trabajo contraídos entre representantes de organismos consulares y representantes de la subcomisión.

Número de capacitaciones efectuadas en enfoque de derechos, género e 2 interculturalidad, $u$ otras, destinadas a los integrantes de la subcomisión.

Número de planes de acción derivados de los acuerdos y memorandos suscritos. 3

Número de acciones implementadas para la articulación y la participación en los 3 espacios de concertación y coordinación interinstitucional e intersectorial con políticas públicas existentes para el fortalecimiento de condiciones de igualdad, equidad y dignidad para el ejercicio de los derechos.

Número de estrategias implementadas para la articulación entre los distintos comités. 
Número de acciones implementadas para la promoción de la cooperación a nivel multilateral, regional, subregional y bilateral para fomentar el intercambio de buenas prácticas y experiencias, así como la asistencia técnica, en la lucha contra la trata de personas.

Número de fuentes de financiación para la ejecución de cada actividad del Plan de 3 Acción, identificada y soportada.

Un plan de acción formulado y aprobado para la vigencia correspondiente por 3 cada comité existente.

Un informe anual de seguimiento al cumplimiento de los compromisos internacionales, adquiridos por Colombia.

Un informe anual relativo a las causas, modalidades, particularidades y 3 consecuencias, para la caracterización y análisis de la trata de personas transnacional producto del intercambio de información con otros países involucrados en el fenómeno.

Número de comités departamentales que adelantarán acciones de cooperación $\quad 3$ bilateral con países fronterizos para la lucha de trata de personas

Número de departamentos fronterizos.

Un informe trimestral de seguimiento a la ejecución de los Planes de Acción nacional, departamental y distrital en materia de trata de personas.

Un informe de evaluación, de gestión, resultados y procesos intermedio y un informe final de evaluación de gestión, resultados y procesos al final de la implementación.

Un informe de evaluación de gestión, resultados y procesos intermedio y un

informe final de evaluación de gestión, resultados y procesos.

Un Informe de evaluación de gestión, resultados y procesos intermedio y un

informe final de evaluación de gestión, resultados y procesos al final de la implementación.

Porcentaje de ejecución del plan o programa con cronograma/100\% de la ejecución.

Número de espacios de discusión y concertación con las Organizaciones de la

Sociedad Civil.

Presupuesto que se aprobó desde el departamento para inversión en actividades 4

de derechos humanos o migración.

Presupuesto que se aprobó desde el departamento específicamente en la línea de $\quad 4$

trata de personas en el presupuesto departamental.

Presupuesto que se aprobó desde el departamento para el funcionamiento del comité departamental de lucha contra la trata de personas.

Presupuesto que se aprobó desde el comité interinstitucional de lucha contra

la trata de personas para actividades de prevención y asistencia y protección e investigación y judicialización en el tema de trata de personas.

Presupuesto que se aprobó para la realización de actividades de asistencia y 4 protección de la trata de personas.

Presupuesto que se aprobó para la realización de actividades de judicialización de 4 la trata de personas.

Presupuesto que se aprobó para la realización de otras actividades de trata de 4 personas.

Presupuesto que se aprobó para la realización de actividades de prevención.

Presupuesto que se aprobó desde la empresa privada para actividades de

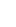

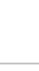

3


Presupuesto que se aprobó desde las organizaciones no gubernamentales para actividades de prevención, asistencia y protección e investigación y judicialización en el tema de trata de personas.

Número de reuniones del comité realizadas en el años / número de reuniones previstas en el año.

Número de miembros del comité que cuenta con más de seis meses de permanencia en el mismo/ número de miembros del comité.

Número de personas asignadas al tema de trata de personas para el departamento.

Número de organismos de cooperación internacional que brindan asistencia al 4 comité departamental, tanto a través de recursos financieros como por medio de aportes en especie.

Número de proyectos de inversión en materia de trata de personas incluidos en el 4 Plan operativo anual de inversiones del departamento.

Responder SÍ o NO, el tema de trata de personas está incluido en el Plan de 4 Desarrollo departamental.

Número de comités municipales y/o distritales creados o fortalecidos con el apoyo 4 del comité departamental.

Número de instituciones del orden nacional, departamental y municipal que

participan / el número de instituciones que deberían participar; número de personas beneficiadas de los programas y acciones interinstitucionales para la prevención, asistencia y reinserción sobre el número de víctimas identificadas. Presupuesto departamental destinado para el programa / el total del presupuesto 5 del programa; porcentaje del presupuesto departamental destinado para el programa.

Número de acciones desarrolladas para la vinculación con organismos nacionales 5 / el total de número de acciones formuladas para la articulación.

Tipo y número de programas formulados departamentalmente que incorporen la estrategia nacional / el total de programas formulados relacionados con la problemática.

Número de estos programas ejecutados o en ejecución que incorporen la estrategia nacional sobre los formulados; nivel de ejecución de cada uno de ellos.

Nivel de ejecución de cada uno de los programas que incorporen la estrategia 5 nacional.

Tipo de instrumentos diseñados para la recolección de la información / instrumentos pertinentes.

Elaborados y publicados los resultados del proceso periódico de monitoreo y evaluación.

Planes operativos anuales elaborados e implementados en el marco de la política 6 pública o el plan nacional.

Creado el órgano rector y designada una secretaría ejecutiva

6

Órgano integrado por personal de alto nivel de las entidades estatales competentes.

Elaborado el plan nacional o la política nacional respectiva.

Elaborados informes anuales sobre las actividades realizadas por el órgano rector 6 en la materia.

Designado el personal capacitado que conforma los órganos de consulta o asesoría técnica.

Las organizaciones especializadas participan activamente en los órganos de consulta y asesoría técnica. 
Conformado un equipo de respuesta rápida con personal técnico especializado

para proteger y asistir a las víctimas

Cantidad de informes y medidas de protección a víctimas realizados por el equipo 6

de respuesta rápida.

Designado el personal técnico y administrativo en cada una de las entidades que 6 conforman el órgano rector.

Establecidos comités locales o grupos territoriales de trabajo; definidos los 6 instrumentos técnicos y de seguimiento a su gestión.

El personal directivo de las entidades que conforman el mecanismo nacional de $\quad 6$ coordinación interinstitucional ha recibido formación y capacitación.

Capacitaciones en todos los ámbitos (atención, protección, prevención, judicialización) integran enfoque de género e incluyen a todos los organismos estatales y no estatales.

Profesionalización de agentes del gobierno, particularmente de la Fuerza Pública, 6 del Ministerio Público y del órgano judicial que están a cargo de la prevención, protección, persecución y judicialización del delito.

Organizaciones de la sociedad civil forman parte, con voz y voto, del ente rector interinstitucional en materia de trata de personas, y participan en la elaboración e implementación del plan nacional/política pública para combatirla.

Organizaciones de la sociedad civil brindan servicios que complementan a los del 6 Estado, especialmente en la atención a las víctimas.

Organizaciones no gubernamentales administran debidamente albergues para 6 víctimas, o facilitan recursos para esos fines.

Participación de entidades privadas en el ente rector interinstitucional.

6

Desarrolladas acciones de responsabilidad social empresarial en materia de 6 prevención, atención y protección a las víctimas.

Elaborados o revisados los protocolos de cooperación interinstitucional en lo que 6 atañe a la investigación de la trata de personas y la asistencia y atención a las víctimas.

Coordinadas las acciones entre organismos estatales, organizaciones no 6 gubernamentales, entidades del sector privado y organizaciones internacionales.

Establecidos compromisos interinstitucionales promovidos por el ente rector.

6

Establecidos convenios de colaboración de carácter bilateral y multilateral.

6

Autoridades nacionales cooperan con autoridades del país de destino o tránsito de 6 las víctimas a fin de concertar su residencia, su retorno o su acceso a programas de asistencia.

Realizadas reuniones de la Coalición Regional contra la trata de personas y el 6 Tráfico Ilícito de Migrantes, en las que se formulan acuerdos y compromisos regionales.

Elaboradas y divulgadas guías y directrices sobre las acciones que los Estados 6 centroamericanos deben emprender para combatir la trata de personas.

Promovidos foros regionales multilaterales donde participan los países de la región 6 comprometidos en la lucha contra la trata de personas.

La pertenencia a la Asociación Iberoamericana de Ministerios Públicos (AIAMP) incentiva la cooperación y la asistencia jurídica mutua.

La autoridad competente presenta y aprueba el presupuesto ordinario para el período fiscal correspondiente. 
Asignado presupuesto especial en los casos establecidos por la ley o por el

reglamento respectivo.

Desde la entrada en vigor de la ley se asigna un presupuesto anual para la lucha 6 contra la trata de personas.

En el presupuesto nacional se asigna un porcentaje para combatir la trata de 6 personas.

Aprobadas partidas presupuestarias de entes locales para la protección a víctimas 6 y la financiación de programas preventivos y programas de apoyo a organizaciones no gubernamentales.

Desde la entrada en vigor de la Ley se incrementa porcentualmente el presupuesto 6 nacional.

El ente rector asigna una partida presupuestaria para las instituciones que lo 6 conforman.

Elaborada una metodología específica para el seguimiento de los presupuestos y $\quad 6$ las acciones en materia de trata de personas.

Elaborados informes periódicos sobre el nivel de ejecución del presupuesto en $\quad 6$ materia de trata de personas.

Mejorados los esquemas de rendición de cuentas a partir de la capacitación del $\quad 6$ personal que interviene en la programación y elaboración de los presupuestos.

Designado el órgano encargado de fiscalizar la ejecución de los fondos públicos en 6 materia de trata de personas.

Evaluada la gestión, los indicadores muestran que los recursos están produciendo 6 los resultados esperados y que la gestión es eficiente, eficaz y transparente.

Cantidad y características de las organizaciones de la sociedad civil que participan 6 en iniciativas de control y ejecución del presupuesto.

Creado el fondo para la prevención, atención y protección a las víctimas.

6

Cobertura de indemnizaciones por daños materiales e inmateriales.

Establecido el procedimiento de gestión y administración del fondo para la asistencia a víctimas.

Se obtienen recursos provenientes de contribuciones, subvenciones y donaciones 6 de instituciones, nacionales o extranjeras, públicas o privadas, así como de organismos internacionales y organizaciones no gubernamentales.

Existe el presupuesto necesario para la atención y protección de las víctimas.

Las autoridades competentes tienen acceso a los recursos destinados a la 6 atención física y psicológica de las víctimas.

Existen los recursos adecuados para gestionar apropiadamente la repatriación de 6 las víctimas.

Existen recursos para implementar programas orientados a facilitar la reintegración familiar, comunitaria, social, educativa, laboral y económica de las víctimas y de sus dependientes.

Existe un presupuesto adecuado para la persecución del delito.

Existen convenios de cooperación y comunicación entre autoridades policiales, migratorias y judiciales para investigar y perseguir el delito de la trata de personas.

Existen acciones de capacitación dirigidas a funcionarios (as) en materia de trata 7 de personas.

7) Generación $y$ gestión del conocimiento
Un observatorio sobre el Delito de la trata de personas, que permita recopilar,

3 internacional, nacional y descentralizado. 
Número de investigaciones y diagnóstico en materia de trata de personas a nivel departamental.

Número de investigaciones y diagnóstico en materia de trata de personas a nivel

3 municipal o distrital.

Número de investigaciones realizadas / el total de las planeadas..

5

Los informes de las instancias externas que dan seguimiento a los compromisos

6 internacionales se elaboran en tiempo oportuno y con información veraz.

Realizadas actividades de investigación académica sobre el tema.

6

Elaborado diagnóstico de la situación nacional que expone las diferentes

6 modalidades de la trata.

Existe un sistema integrado y homogeneizado de estadísticas.

Promovidos para la ciudadanía los mecanismos de acceso a la información sobre

la trata de personas.

Informe cualitativo en materia de trata de personas elaborado.

Número de buenas prácticas detectadas en análisis de casos.

2

Número de personas beneficiadas con capacitaciones acerca del delito de trata de 1 personas. 